Pérez Ballester, J. (2018): “Cerámicas engobadas púnico-helenísticas de Ibiza y Cerdeña (siglos III-II a.C.). Ordenación funcional”, Spal 27.2: 165-199. DOI: http://dx.doi.org/10.12795/spal.2018i27.19

\title{
CERÁMICAS ENGOBADAS PÚNICO-HELENÍSTICAS DE IBIZA Y CERDEÑA (SIGLOS III-II a.C.). ORDENACIÓN FUNCIONAL
}

\author{
PUNIC-HELLENISTIC SLIPPED POTTERY OF IBIZA AND \\ SARDINIA (III-II BC). FUNCTIONAL ORDINATION
}

\author{
JOSÉ PÉREZ BALLESTER \\ Grupo de investigación arqueológica en el Mediterráneo GRAM. Dpt. Prehistòria, Arqueologia i Historia Antiga, (Universitat de València) \\ Correo-e: jose.perez-ballester@uv.es. ORCID: https://orcid.org/0000-0003-0091-6361
}

\begin{abstract}
Resumen: Presentamos una ordenación funcional de las cerámicas engobadas púnico-helenísticas de Cerdeña e Ibiza, basada en los abundantes trabajos existentes así como en nuestra experiencia directa en Cerdeña (Pauli Stincus y Truncu e'Molas) e Ibiza (Can Vicent d'en Jaume). Pondremos estas producciones en relación con otras similares del Mediterráneo Central y Occidental: costas del África mediterránea (Cartago, Orán, etc) y área del Estrecho (bahía de Cádiz, Lixus, Kuass). Se propone una evolución cronológica y una aproximación a los usos y funcionalidad de esta vajilla de mesa púnica.
\end{abstract}

Palabras clave: Período helenístico; cerámica púnica; imitaciones; Mediterráneo centro-occidental; Kuass; Cádiz.

\section{INTRODUCCIÓN}

Las cerámicas engobadas púnico-helenísticas son conocidas en la bibliografía como imitaciones locales de barniz negro o "cerámicas púnicas de barniz negro", incidiendo en muchos casos en su carácter de pertenencia a una koiné púnico-helenística del Mediterráneo Central y Occidental.

Efectivamente, J.P. Morel (1980) al hablar de las cerámicas púnicas de barniz negro, señalaba que ese "barniz" (Cuomo di Caprio 2007: 295) era muy diluido y se combinaba con el rojo en el mismo vaso; indicaba
Abstract: This paper offers the functional ordination of the slipped Punic-Hellenistic pottery produced in Sardinia and Ibiza, based on numerous published research and in our direct experience in Sardinia (Pauli Stincus and Truncu e' Molas sites) and Ibiza (Can Vicent d'en Jaume). We will put this ceramics in relation to other centers of production of Western and Central Mediterranean: African Mediterranean coast (Carthage, Oran) and Gibraltar Strait Area. We propose a chronological evolution and an approach to the use and functionality of this Punic tableware.

Keywords: Hellenistic period; Punic pottery; imitations; Central and Western Mediterranean; Kuass; Cádiz.

también que aquellos fabricados en los márgenes del mundo púnico (Ibiza, Marruecos) presentaban caracteres análogos. Más adelante lo entendería como un fenómeno de difusión de un repertorio formal y unas técnicas de fabricación comunes al mundo púnico (Morel 1986) de Cartago a Gadir y Kuass y de Cerdeña a las costas mediterráneas de la península ibérica, pasando por Ibiza.

En 1992 precisaba que en los siglos III-II a.C., "en regiones moderadamente impregnadas de la cultura cartaginesa se hacian imitaciones pero realizadas... con una técnica que no tiene que ver con el barniz 
negro, o también, con un gusto que prefiere otras soluciones cromáticas, en especial el rojo". Las distinguía de las imitaciones locales más directas de las producciones campanienses, ya de los siglos II-I a.C., con superficies cubiertas por "... un barniz negro, gris, rojo, sin barniz incluso, o decorado con bandas pintadas" (Morel 1992: 1720-1722).

Estas opiniones hicieron que los ceramólogos no dudasen en interpretar esas producciones helenísticas de vajilla de mesa, fechables en los siglos III-II a.C. e incluso algunas del siglo IV a.C., como "imitaciones locales de barniz negro" o "cerámicas púnicas de barniz negro" (Campanella 1999 y 2008; Garau 2006; Del Vais 2007; Tronchetti 2001, 2008, etc; Bechtold 2010, 2014; Ramon 2012a y b).

Tras nuestros trabajos sobre materiales de Cartagena, Ibiza y Cerdeña, estudiando allí las cerámicas engobadas de Pauli Stincus (Terralba, Oristano) y más tarde con la revisión de las de Neápolis (Oristano), tuvimos la certeza de que nos encontrábamos no ante imitaciones de barniz negro, sino ante una producción de vajilla de mesa engobada que se diferenciaba de aquellas (Pérez Ballester 2009: 263-274). En un reciente trabajo (Pérez Ballester e.p.) creemos demostrar, con la ayuda de estudios cuantitativos y de análisis arqueométricos, que estamos ante piezas fabricadas en el seno de una misma tradición cerámica púnico-helenística, que con ligeras diferencias pueden identificarse en Ibiza, Cerdeña, también en Cartago, el área atlántica del Estrecho y seguramente en Sicilia, entre los siglos III y II a.C. como ya indicaba J.P. Morel. Este estado de cosas irá desapareciendo con el predominio de la vajilla romana republicana de barniz negro a partir de la mitad del s. II a.C.

\section{HISTORIA DE LA INVESTIGACIÓN}

En Cerdeña, estas cerámicas engobadas se produjeron en hornos como los que desde el siglo VI a.C. cocían vasos y jarras con bandas pintadas en color rojo, castaño o anaranjado. Con esta tradición de base, a partir de fines del siglo IV comienza a realizarse una vajilla que reproduce primero formas del repertorio ático (Tronchetti 2014), y luego otras cerámicas helenísticas de barniz negro itálicas, pero posiblemente también cartaginesas o del mundo púnico centromediterráneo.

Fue Rhigini Cantelli (1981) quien refiriéndose a Tharros, definió esta vajilla barnizada o engobada con el nombre algo despectivo de cerámica "chiazzata": de barro poco cocido, porosa y harinosa, de colores diversos y superficie recubierta de un engobe opaco, resquebrajable, a veces espeso o a veces diluido, de color variable entre el negruzco, castaño, castaño-rojizo o grisáceo.

C. Tronchetti, uno de los investigadores que más estudios ha dedicado a las cerámicas áticas de barniz negro en Cerdeña, se ha interesado también por estas cerámicas locales, precisando (Tronchetti 1991: 1277) que durante el siglo III “... se desarrollan oficinas locales que se inspiran en las cerámicas áticas y centroitálicas, pero también hay algunas de tradición local o incluso púnica ...que cubrirán las necesidades del mercado local a partir de la mitad del siglo III y durante el siglo II seguirán imitando las formas de barniz negro itálico". Diez años después (Tronchetti 2001: 275) caracterizará una de estas producciones, la "Cagliari 1", con una acertada definición: "producción local que se inspira en las de barniz negro importadas de las que derivan la forma, técnica y decoración, pero con una óptica local y dentro de un medio temporal y geográfico del occidente púnico o punicizante". Es decir, distingue el grupo de imitaciones de las cerámicas de barniz negro áticas o itálicas, con formas y decoración a menudo similares, donde incluye a las de Cerdeña que estamos estudiando; y las diferencia del equívoco concepto de "cerámicas de imitación de barniz negro", que presupone que aunque de imitación, tienen una cubierta de color negro, que sin embargo no es nada frecuente en las producciones sardas.

Por último separa de este grupo las llamadas "cerámicas de barniz negro con pasta gris" o "gris sarda", que se distribuyen por toda Cerdeña a finales del siglo II y durante el siglo I a.C., hechas con cocción reductora y a menudo con una cubierta negra, e imitan claramente formas campanienses entre las que predominan las formas Lamb. 1 y Lamb. 5. Este fenómeno lo encontramos también en regiones tan alejadas como el Bajo Guadalquivir (Ramos Suárez y García Vargas 2014) o en Andalucía Oriental, en los mismos momentos (Adroher y Caballero 2012).

L. Campanella (1999: 95), al estudiar las de Monte Sirai, las definió como "cerámicas de barniz negro de producción local" intentando seguir la corriente general imperante, aunque admite que “...en realidad el barniz no es siempre negro, sino que se presenta gris, marrón y a menudo rojo y anaranjado. No podemos excluir que el brillante barniz rojo de muchos ejemplares fuese el resultado de un efecto intencionado”. Más adelante, al hablar de las cerámicas barnizadas de Sulkis reconoce la preferencia por las tonalidades rojizas en Cerdeña, quizás una opción intencionada (Campanella 2008: 165). 
E. Garau (2006: 265), refiriéndose a las del área de Neápolis, las denomina “....una producción local de cerámica de barniz negro, de pasta beige clara y barniz mate, cubriente, que a veces se craquela, de color no uniforme, entre el rojo anaranjado y el marrón". Hace hincapié, en que "...las distintas producciones de centros insulares como Tharros, Carales, Olbia, Nora, nos están hablando de una koiné a la que pertenece también Neápolis, aunque con peculiaridades propias" (2006: 271).

C. Del Vais, tanto en su excelente puesta al día (2007) de la producción que denomina "cerámica punica de barniz negro", como en sus trabajos especialmente con M.L. Amadori en Tharros (2004), Pantelleria (2006) y Olbia (2009), utiliza los análisis petrográficos y mineralógicos para señalar producciones locales e incluso importaciones del área de Cartago (Bechtold 2014: 97). Prefiere sin embargo seguir llamando a estas producciones "de barniz negro", aunque por ejemplo, al estudiar las piezas de Olbia los análisis confirman que el tipo de cocción, parcialmente reductora, hace imposible que se produjeran barnices negros (Amadori et al. 2009: 119). En análisis mineralógicos sobre muestras de Tharros (Amadori et al. 2004: 39-40) comprueba que de tres grupos bien diferenciados visualmente (uno de pasta gris, otro de pasta oxidante clara y engobes oscuros y un tercero de pasta anaranjada y engobe anaranjado), todos tienen la misma composición mineralógica y la misma procedencia, local en este caso. Por ella sabemos también de la existencia de talleres u oficinas arqueológicamente constatadas, aunque no excavadas, que producían estas vajillas en los alrededores de Tharros y en Olbia (Del Vais 2007: 172-173).

En Ibiza, después de la publicación de M. Del Amo (1970) en donde se dieron a conocer por vez primera estas cerámicas engobadas, será V. Guerrero $(1980,1984$, 1997, 1998 y 1999 principalmente) quien, a partir del estudio de la factoría, el pecio y el fondeadero de $\mathrm{Na}$ Guardis en Mallorca ordenará y sistematizará esta producción de vajilla de mesa engobada, que se presenta bajo cocción oxidante o reductora. El autor asoció su repertorio formal a la tipología de las campanienses de Lamboglia, aunque las consideró "pseudocampanienses" siguiendo una terminología común en la época, porque en general no imitaban fielmente a la vajilla itálica de barniz negro, y algunas de las formas ya revelaban una filiación más púnica u occidental que tirrénica (Guerrero 1980: 169). Ya adelantó, como J.P. Morel, que "...parece que nos encontramos en el seno de una tradición cerámica púnica que puede arrancar desde las producciones del llamado "barniz rojo occidental", y que “... encontramos también en época helenística en lugares como Cerdeña o área del Estrecho además de la propia Ibiza, que refleja en su vajilla la variedad formal de su entorno" (Guerrero 1980: 171).

La cubierta de estas cerámicas solo muy excepcionalmente presenta un engobe semivitrificado o "sinterizado" como el de las cerámicas áticas, campanienses o sigilatas y que se suele denominar barniz.

Ha sido J. Ramon (1993, 1994, 1997, 1998a y b, 2012a y b) quien ha excavado y publicado más lugares con depósitos y talleres alfareros en la ciudad de Ibiza, donde se concentraba la producción cerámica ebusitana. En lo referente a la vajilla de mesa, reconoce una tradición de cerámica gris inicial (siglos VIV a.C.) realizada a fuego reductor con formas que copian claramente a las áticas (Fernández y Granados 1980); apareciendo las producciones oxidantes "de barniz negro" a finales del siglo IV, con una rápida extensión durante todo el III y gran parte del siglo II a.C. (Ramon 2012a: 586; 2012b: 231). Pero en realidad esa cubierta no es negra. En yacimientos de la segunda mitad del III como HX-1, FE-13, AR-33/V, describe la vajilla de mesa oxidante con "pintura continua" o "tinte" y colores predominantes marrón, marrón rojo, negro, rojizo o anaranjado (1994: 45; 1997: 18-19, 21, etc; 1998b: 162-163). Sí comenta que a partir del s. II “...el barniz negro, en esta época no es generalmente sino una pintura preferentemente rojiza frecuentemente de muy mala calidad" (Ramon 2012a: 607ss; 2012b: 233).

\section{LOS YACIMIENTOS (fig. 1)}

En este trabajo, hemos considerado para Cerdeña los siguientes yacimientos: Tharros (Rhigini Cantelli 1981; Amadori et al. 2004), el Sinis (Del Vais 2014) Cagliari (Tronchetti 1991 y 2001), Monte Sirai (Campanella 1999), Sant'Antioco-Sulkis (Campanella 2008), Olbia (Amadori et al. 2009) y Neápolis (Garau 2006), así como la síntesis de Del Vais (2007) sobre esta clase de cerámicas. También incluimos los estudiados personalmente procedentes del asentamiento rural púnico de Pauli Stincus (Díes Cusí et al. 2010; Roppa 2013) en Terralba (Oristano), área donde participamos en diferentes proyectos de investigación (Van Dommelen y Sharpe 2004), al que se unieron en 2007 C. Gómez Bellard y yo mismo de la Universitat de València. Los materiales considerados pertenecen a la segunda fase del asentamiento, un hábitat rural cuya construcción es anterior a la ocupación romana, seguramente de la 


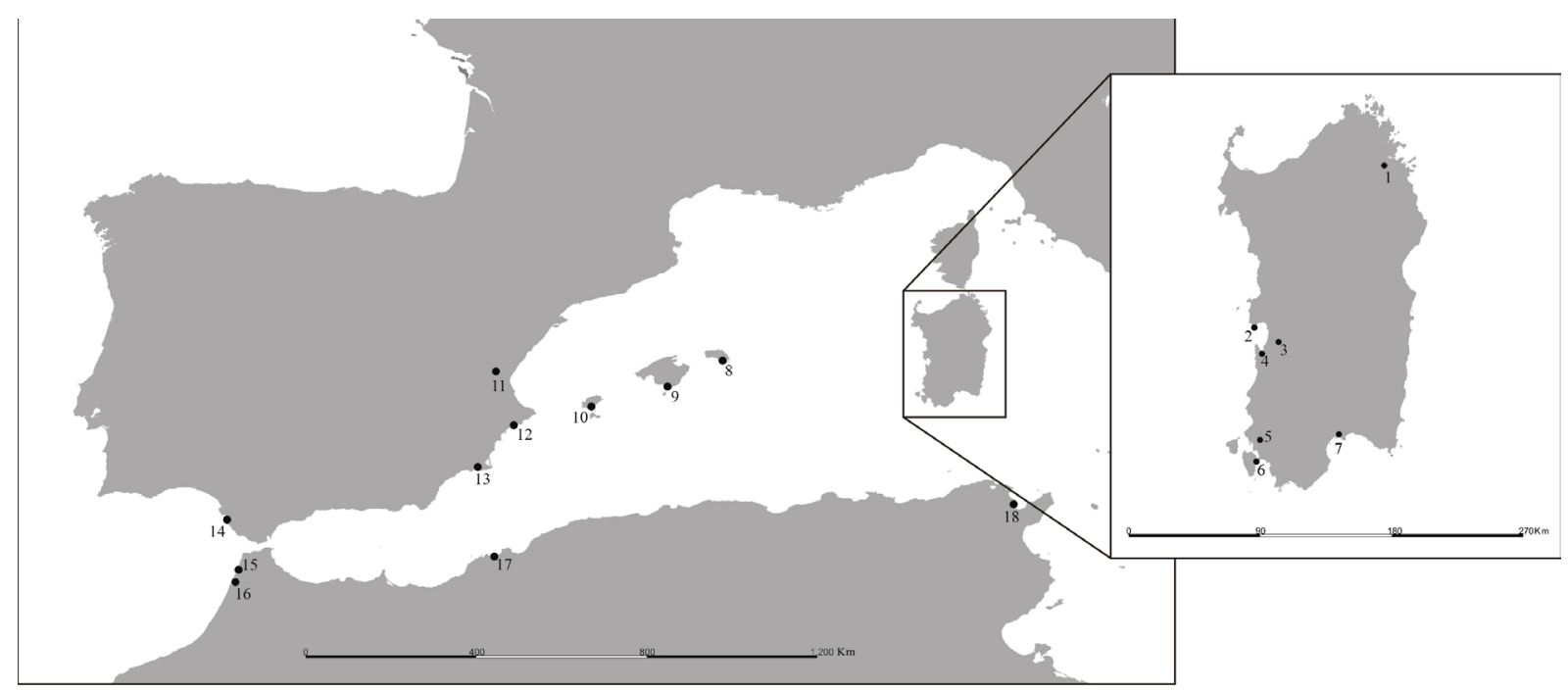

Figura 1. Mapa con la ubicación de los principales yacimientos mencionados en el texto. 1: Olbia. 2: Tharros. 3: Pauli Stincus. 4: Neapolis. 5: Monte Sirai. 6: Sulkis. 7: Caralis. 8: Cales Coves. 9: Na Guardis. 10: Ebussus. 11: Tossal de Sant Miquel. 12 : La Malladeta. 13: Carthago Nova. 14: Gadir. 15: Kuass. 16: Lixus. 17: Orán. 18: Carthago.

primera mitad o mediados del siglo III a.C. y que se abandona a fines del II o inicios del siglo I a.C.

Para Ibiza y Pitiusas, son fundamentales los trabajos de síntesis de Joan Ramon (1998a y 2012a y b) y otros muchos específicos sobre distintas excavaciones en Ibiza como hemos comentado en el apartado anterior. Hemos añadido el estudio del vertedero de S'Olivar d'es Mallorquí (Gómez Bellard 1995); en cuanto a las necrópolis, el Puig des Molins (Fernández Gómez 1992) y las necrópolis rurales ibicencas (Tarradell y Font 2000). Por último, mencionamos nuestro trabajo de síntesis sobre este tipo de cerámicas (2009) y el de Can Vicent d'en Jaume (Pérez Ballester y Gómez Bellard 2009), así como el taller de L'Avinguda d'Espanya 3 (Duarte 2016) cuyos materiales hemos podido consultar personalmente. Para las Baleares son fundamentales los trabajo de Guerrero en el fondeadero púnico de Na Guardis en Mallorca (Guerrero 1984) y los diferentes trabajos de síntesis sobre las cerámicas púnicas de Mallorca del mismo autor (1980, 1997, 1998 y 1999b); junto a ellos, el poblado del Turó de les Abelles (Camps y Vallespir 1998).

En Menorca, hemos recogido los hallazgos en el fondeadero de Cales Coves (Fernández Miranda y Belén 1977; Belén y Fernández Miranda 1979).

Ya en la península ibérica, encontramos cerámicas engobadas en la fachada mediterránea oriental: Cartagena, con los estudios de Martín Camino (1998), la tesis doctoral de E. Ruiz Valderas (2000), o nuestros propios trabajos sobre el área del Anfiteatro (Pérez Ballester 1995, 1998 y 2000). En tierras valencianas, las encontramos en el Tossal de Sant Miquel de Llíria (Bonet y Mata 1988 y 2002) y en el posible santuario de La Malladeta, en la Vila Joiosa (Alicante) (Rouillard et al. 2014: 109-121).

En el área del Estrecho, los talleres de la bahía de Cádiz con las producciones "tipo Kuass" son fundamentales. Reproducen en los primeros momentos (finales del siglo V y siglo IV a.C.) fielmente las formas de la vajilla griega y luego las de otras producciones itálicas y también púnicas. Los hemos estudiado a través de las publicaciones de A.M. Niveau de Viledary sobre la tipología y cronología de estas cerámicas (2003 y 2009 principalmente), así como sobre su funcionalidad (2014).También hemos tenido en cuenta las precisiones sobre la cronología y distribución de las cerámicas tipo Kuass de Sáez Romero (2014) y el estudio sobre el Bajo Valle del Guadalquivir de Moreno Mejías (2016) sobre su adaptación y consumo en el mundo indígena del interior.

En la costa atlántica norteafricana, los trabajos de Kbiri Alahui en Kuass (2007) y Aranegui et al. (2001, 2005 y 2010) en Lixus recogen cerámicas engobadas de talleres locales o regionales, así como del área de Cádiz.

Para la costa mediterránea de Marruecos y Argelia, hemos revisado los hallazgos de Orán (Vuillemot 1965, Bridoux 2006) y los trabajos sobre Numidia y Mauritania de V. Bridoux (2006 y 2008). 
Sobre Cartago disponemos de poca documentación. Hemos utilizado la tipología sobre la cerámica púnica de S. Lancel (1987) y los estudios sobre periodización de cerámicas púnicas de época helenística de $\mathrm{B}$. Bechtold (2007 y 2014).

\section{UNA ORDENACIÓN FUNCIONAL}

Nuestra experiencia directa en Ibiza y Cerdeña nos hizo ver que no solo había una manera común de fabricar estas cerámicas (Pérez Ballester e.p.), sino que el repertorio formal era muy similar en todo el ámbito púnico del Mediterráneo Central y Occidental. Es por ello, por lo que presentamos esta ordenación funcional que recoge tipologías que se propusieron anteriormente para Ibiza (Guerrero 1999), bahía de Cádiz (Niveau 2003 y 2009), Kuass (Kbiri Alaoui 2007) o de manera más genérica, en Cartago (Lancel 1987). También hemos tenido en cuenta las propuestas funcionales para la cerámica ática de Bats (1988); de Principal (1998) para las producciones de barniz negro del siglo III en Cataluña, la de la cerámica ibérica de Mata y Bonet (1992) y las de Niveau (2003 y 2009) y Sáez Romero (2014) para las de tipo Kuass.

Proponemos agrupar las distintas formas en cinco series definidas por nombres descriptivos cercanos que sugieren posibles usos: Platos (I), Páteras (II), Cuencos Profundos (III), Cuencos Poco Profundos (IV), Cuencos Anchos Poco Profundos (V) y un último grupo para vasos de forma o funcionalidad diversa, como las píxides y las tapaderas, el grupo de Varios (VI).

Esta ordenación tiene su base en características formales como su mayor o menor profundidad, reflejada en el índice rdp o relación entre el diámetro del borde y la profundidad del vaso; la orientación del borde, exvasado, recto o reentrante, que facilita o no su utilización como recipiente para beber o para contener alimentos más o menos sólidos, etc.

Añadimos al nombre en castellano el mismo en italiano, francés e inglés, para mejor relacionarlo con publicaciones existentes en esas lenguas.

Las referencias a la tipología de Morel (1981) sobre las cerámicas de barniz negro son obligatorias, ya que estas cerámicas son el grupo más importante de la vajilla de mesa helenística del Mediterráneo, y muchas de sus formas son comunes o similares a las púnico-helenísticas que estudiamos. La alusión a la clasificación de Lamboglia es igualmente obvia cuando es posible; así como a la cerámica ática de barniz negro del Ágora de Atenas (Sparkes y Talcott 1970). Ya en las distintas variantes, se alude igualmente a las clasificaciones mencionadas de Guerrero (1999), Niveau (2003), Kbiri Alaoui (2007) o Lancel (1987).

I: Plato (It: piatto; Fr: plat, asiette, patère; Ingl: plate, dish). Se trata de formas abiertas, de borde exvasado, sin asas. Todas se situarían dentro de la categoría F-1000 de Morel. Los diámetros de borde están entre 18 y 26 $\mathrm{cm}$, aunque pueden aparecer algunos de menor formato. La relación entre el diámetro del borde y la profundidad del vaso, en adelante: rdp, oscila entre 5 y 10 .

I-1 a: Plato de borde colgante al exterior (fig. 2). Es una forma frecuente en las cerámicas de barniz negro itálicas desde inicios del siglo III (Lamb. 36) con especial presencia a partir del último cuarto de ese siglo y hasta el I a.C., dentro de la producción de la Campaniense A. Corresponde a las especies F-1310/20 de la clasificación de Morel.

En Cerdeña la encontramos en un formato pequeño $(12-13 \mathrm{~cm})$ y otro mayor, más frecuente: $17-20 \mathrm{~cm}$, con rdp variable entre 5 y 8,5 .

En Ibiza y Baleares predominan los de cocción reductora sobre los oxidantes, siendo los primeros de menor diámetro $(14-18 \mathrm{~cm})$ y los segundos mayores (20-26 cm). La rdp varía entre 6,5 y 10 , similar a la de Cerdeña. (Tabla 1)

I-1b: Platito de borde ligeramente colgante (fig. 2). Recuerda a la forma F-1514 de Morel.

Solo la encontramos en Cerdeña, con diámetros de borde entre $8 / 10 \mathrm{~cm}$ y rdp entre 7,5 y 12,5 . (Tabla 2 ).

\section{I-2: Plato de borde colgante y pocito central (fig. 2).}

Se trata del conocido como "plato de pescado", que documentamos en las cerámicas áticas de figuras rojas y barniz negro, así como en las producciones itálicas de barniz negro, Talleres Occidentales (Roses) y cerámicas engobadas del área del Estrecho, entre otras. Corresponde a la forma 23 de Lamboglia, o la especie F-1120 de Morel. Para Niveau y Campanella (2006: 670-680) la forma surgiría en época helenística como resultado de la convergencia de tradiciones alfareras griegas y fenicias debido a la mayor presencia de alimentos sólidos proteínicos (pescado especialmente) cocinados de una manera determinada.

Los formatos son similares en ambas islas: en Cerdeña los diámetros de borde se mueven entre 18 y 23 $\mathrm{cm}$, y la rdp está entre 6 y 7; en Ibiza los diámetros se centran también entre los 19 y $22 \mathrm{~cm}$, aunque hay algunos de $26 \mathrm{~cm}$. La rdp denota platos algo menos profundos, entre 6,5 y 8,3 . 
Tabla 1.

\begin{tabular}{|c|c|c|c|}
\hline Área & Yacimientos & Cronología & Bibliografía \\
\hline \multirow{3}{*}{ Cerdeña } & - Cagliari & \multirow{3}{*}{$\begin{array}{l}\text { mitad III-mitad II a.C. } \\
1^{\text {a }} \text { mitad II a.C. }\end{array}$} & \multirow{2}{*}{$\begin{array}{l}\text { Tronchetti } 2001: 282 \text {, láms II y III; } \\
\text { Del Vais 2007: 178; 2014: 117, fig. 11, } 36\end{array}$} \\
\hline & - Sinis & & \\
\hline & $\begin{array}{l}\text { - Neápolis, Pauli Stincus y Truncu } \\
\text { e'Molas }\end{array}$ & & (Inéditos) \\
\hline Ibiza & - Can Vicent & II a.C. & $\begin{array}{l}\text { Pérez Ballester y Gómez Bellard 2009: } \\
\text { 29-30, fig. } 3\end{array}$ \\
\hline Baleares & - Na Guardis & 225-190 a.C. (gris) & Guerrero 1999: fig. 11, tipo II.2 \\
\hline \multirow{2}{*}{$\begin{array}{l}\text { Fachada } \\
\text { Mediterránea }\end{array}$} & - Cartagena & \multirow{2}{*}{ antes del 130-120 a.C. } & Ruiz Valderas 2000 \\
\hline & - Tossal de S. Miquel y La Albufereta & & Bonet y Mata 1988: 20; Bonet 1996: 391 \\
\hline \multirow{2}{*}{ Estrecho } & - Bahía de Cádiz (forma V) & \multirow{2}{*}{ II a.C. } & Niveau 2003: 147 \\
\hline & - Lixus & & Bonet et al. 2005: 137-138 \\
\hline \multirow[t]{2}{*}{ N. de África } & - Orán & \multirow[t]{2}{*}{$1^{\mathrm{a}} \operatorname{mitad} \mathrm{s} . \mathrm{II}$ a.C. } & $\begin{array}{l}\text { Vuillemot 1965: } 359 \text {, sep. } 39 \text {, n.2; Bridoux } \\
\text { 2006: 1662, fig.3 }\end{array}$ \\
\hline & - Cartago & & Bechtold 2014: 106, fig. 7c \\
\hline
\end{tabular}

Tabla 2.

\begin{tabular}{|l|l|c|l|}
\hline \multicolumn{1}{|c|}{ Área } & \multicolumn{1}{|c|}{ Yacimientos } & Cronología & \multicolumn{1}{c|}{ Bibliografía } \\
\hline Cerdeña & Pantelleria (Sicilia) & \multirow{2}{*}{ III-II a.C. } & Del Vais 2007: fig. 1, 16 \\
\cline { 1 - 2 } Sicilia & Pauli Stincus & & (Inéditos) \\
\hline
\end{tabular}

En Cerdeña se atestigua siempre en cocción oxidante en casi todos los yacimientos revisados, aunque en escaso número. En Ibiza coexisten los de cocción reductora (desde el siglo IV) con los oxidantes. Muy abundantes desde la mitad del III, continúan durante todo el II e inicios del siglo I a.C.

En la fachada mediterránea de la península ibérica es una de las formas más frecuentes, de origen ibicenco, pero mayoritariamente en cocción reductora.

En el área atlántica del Estrecho, tanto en la bahía de Cádiz como en Kuass es la forma más numerosa. En la bahía de Cádiz sus tamaños son similares a los de Cerdeña e Ibiza: entre 18 y $22 \mathrm{~cm}$ de diámetro de borde. En Kuass sin embargo son de pequeño tamaño, con diámetros entre 13 y $15 \mathrm{~cm}$. (Tabla 3 ).

\section{I-3: Plato de borde horizontal (fig. 2).}

Plato de borde ancho, plano y casi horizontal, que recuerda a otros de barniz negro de las especies F-1730/40 de Morel. Más bien parece un plato local inspirado en los morteros ibicencos y cartagineses de la misma forma y mayor tamaño, que una imitación itálica. Los contextos remiten al siglo II a.C.

No se documenta en Cerdeña. En Ibiza son escasos, con diámetros entre 20 y $21 \mathrm{~cm}$ y rdp variable, entre 3'7 y 6,3. Allí aparece en cocción reductora; pero en Lixus está en cocción oxidante (Bonet et al. 2005: 137138). (Tabla 4).

I-4: Plato con borde horizontal ondulado, aprox. F-1634 de Morel, parecido a la serie de plates of rilled rim del Ágora (Sparkes y Talcott 1972: nº1022-1031) (fig. 2).

En Cerdeña está con un diámetro de $20 / 24 \mathrm{~cm}$ y rdp entre 6 y 14; en Ibiza con diámetro de $24 \mathrm{~cm}$ y rdp de 9. (Tabla 5).

II: Pátera (It: piatto, patere; Fr: patère; Ingl: plate, saucer). Formas abiertas, de borde reentrante o recto, sin asas. Todas dentro de las especies F-2160/70 o del género F-2200 de Morel. Los diámetros de borde están entre 16 


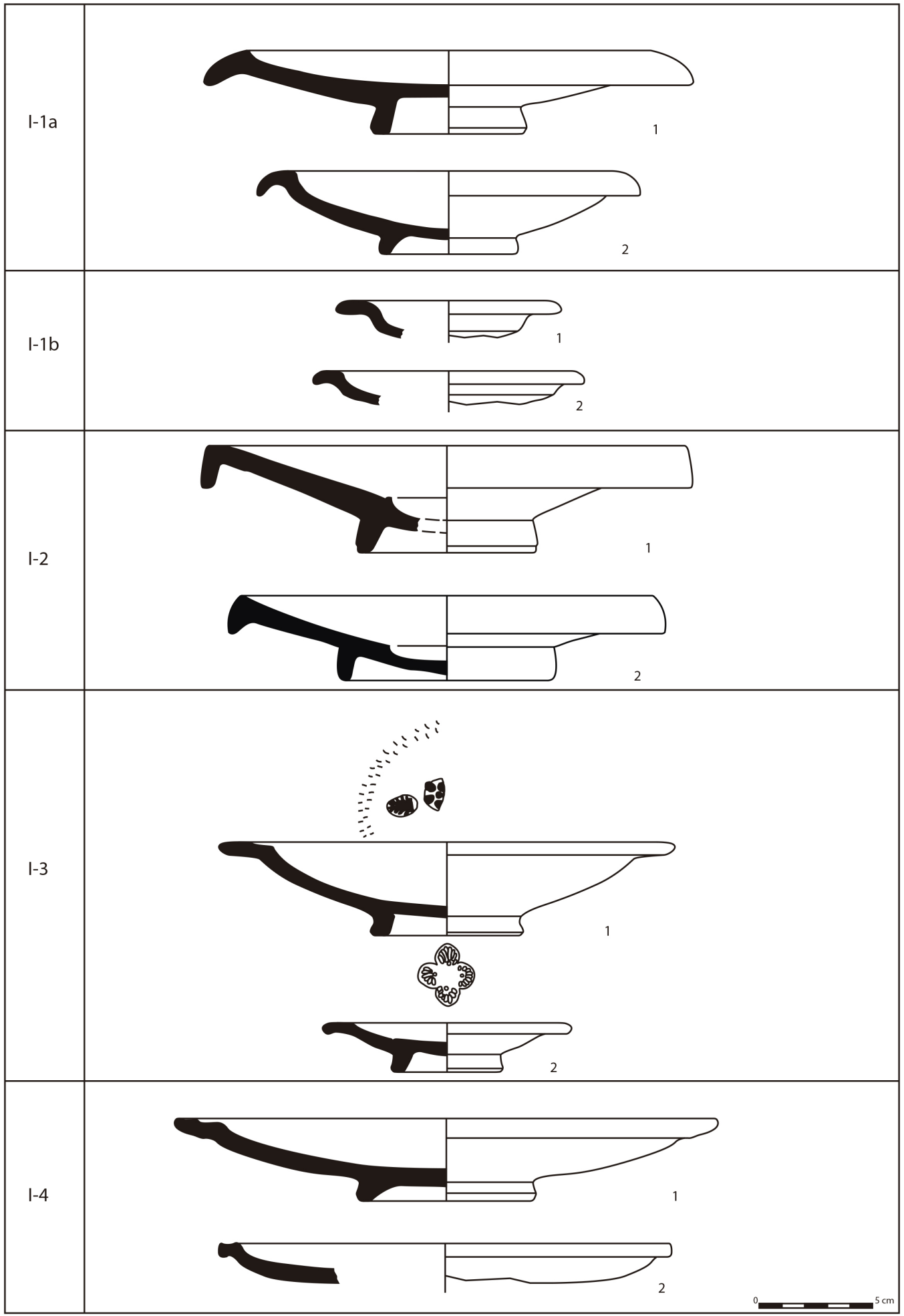

Figura 2. I-1a.1: Ibiza, AE-34. 2: Cagliari, Tomba di Bonaria. I-1b. 1: Pauli Stincus. 2: Pauli Stincus. I-2. 1: Ibiza, FE-13. 2: Olbia. I-3. 1: Na Guardis (Mallorca). 2: Cagliari, Cisterna della Cittadella. I-4. 1: Cales Coves (Menorca). 2: Olbia. 
Tabla 3.

\begin{tabular}{|c|c|c|c|}
\hline Área & Yacimientos & Cronología & Bibliografía \\
\hline \multirow{7}{*}{ Cerdeña } & - Monte Sirai & $2^{\mathrm{a}}$ mitad III a mitad II a.C. & Campanella 1999: fig. 20 \\
\hline & - Olbia & III-II a.C. & Amadori et al. 2009: fig. 2, Olb 12 \\
\hline & - Tharros & III-II a.C. & Amadori et al. 2004: fig. 2, 10 y 11 \\
\hline & - el Sinis & III-II a.C. & Del Vais 2014: 117, fig. 11, 32-35 \\
\hline & - Cagliari & mitad III a mitad II a.C. & Tronchetti 2001: 280-283, láms. I a IV \\
\hline & - Neápolis & & Museo de Oristano \\
\hline & - Pauli Stincus & & (inédito) \\
\hline \multirow{3}{*}{ Ibiza } & - Ibiza & mitad III a fin II a.C. & $\begin{array}{l}\text { Ramon 2012a: 35-39, fig. 6; 594; 607, } \\
\text { fig. 13, } 113\end{array}$ \\
\hline & - Can Vicent & $2^{\mathrm{a}}$ mitad II a.C. & $\begin{array}{l}\text { Pérez Ballester y Gómez Bellard 2009: } \\
\text { 24-26, figs. } 1 \text { y } 2\end{array}$ \\
\hline & - Avinguda d'Espanya & III a mitad II a.C. & Duarte 2016: 65-79 figs. 9-12 \\
\hline Baleares & - Na Guardis & $\begin{array}{l}2^{\mathrm{a}} \operatorname{mitad} \text { III a } \\
\text { mitad del II a.C. }\end{array}$ & $\begin{array}{l}\text { Guerrero 1999: 17, tipo II.3, fig. 12, 2-4; } \\
\text { 12a, 5-8 }\end{array}$ \\
\hline \multirow{6}{*}{$\begin{array}{l}\text { Fachada } \\
\text { Mediterránea }\end{array}$} & - La Malladeta & \multirow{6}{*}{$\begin{array}{c}3^{\circ} \text { tercio III a } \\
1^{\circ} \text { cuarto II a.C. }\end{array}$} & Rouillard et al. 2014: 109, fig. 118 \\
\hline & $\begin{array}{l}\text { - Tossal de S. Miquel y Puntal dels } \\
\text { Llops }\end{array}$ & & $\begin{array}{l}\text { Bonet y Mata 1988: 18; ídem 2002: } 151 \text {, } \\
\text { fig. } 85 \text { y 94; Bonet 1996: 390, fig. } 53 \text { y } 98\end{array}$ \\
\hline & - Cartagena & & $\begin{array}{l}\text { Ruiz Valderas 2000; Martín Camino 1998: } \\
\text { 14, lám. IX }\end{array}$ \\
\hline & $\begin{array}{l}\text { - Los Nietos, Cabecico del Tesoro } \\
\text { (grises) }\end{array}$ & & Page 1984:¿?-175 \\
\hline & $\begin{array}{l}\text { - Tossal de la Cala, La Escuera, La Co- } \\
\text { valta d'Albaida y La Serreta (grises) }\end{array}$ & & $\begin{array}{l}\text { Grau 2002: 167-168 y 271; Abad y Sala } \\
\text { 2001: } 252\end{array}$ \\
\hline & - S. Pere Gros y La Massana (Cataluña) & & Principal 1998: 68 \\
\hline \multirow{3}{*}{ Estrecho } & - Bahía de Cádiz & fines IV a II a.C. & Niveau 2003: 147, forma II. \\
\hline & - Kuass & \multirow{2}{*}{ III-II a.C. } & $\begin{array}{l}\text { Kbiri Alaoui 2007: 175-177, figs. 144-147, } \\
\text { forma } 1\end{array}$ \\
\hline & - Lixus & & Bonet et al. 2005: 135-137 \\
\hline \multirow{2}{*}{ N. de África } & - Orán & \multirow{2}{*}{$\begin{array}{l}2^{\mathrm{a}} \operatorname{mitad} \text { III a } \\
\text { mitad II a.C. }\end{array}$} & $\begin{array}{l}\text { Vuillemot 1965: } 349 \text { no2, 359, nº3; Bridoux } \\
\text { 2006: } 1660 \text {, fig. } 3\end{array}$ \\
\hline & - Cartago & & Bechtold 2014: 102, fig. 6c; 106, fig. 7 a-b \\
\hline
\end{tabular}

y $22 \mathrm{~cm}$, y las rdp se sitúan habitualmente entre 4 y 8 , aunque hay excepciones que pueden llegar a 12-20. Funcionalmente, algunas podrían agruparse con los platos.
II-1a: Pátera de paredes tensas, con borde levemente engrosado al interior (fig. 3). Aproximadamente F-2233/34 de Morel, o Lamb. 55. 
Tabla 4.

\begin{tabular}{|l|l|c|l|}
\hline \multicolumn{1}{|c|}{ Área } & \multicolumn{1}{|c|}{ Yacimientos } & Cronología & \multicolumn{1}{c|}{ Bibliografía } \\
\hline \multirow{2}{*}{ Ibiza } & - Can Vicent & $2^{\text {a } \text { mitad II a.C. }}$ & Pérez Ballester y Gómez Bellard 2009: 30, fig. 3 \\
\cline { 2 - 4 } & - Avinguda d'Espanya & III-II a.C. & Duarte 2016: 70, fig. 13 \\
\hline \multirow{2}{*}{ Baleares } & - Na Guardis & 150/130 a.C. & $\begin{array}{l}\text { Guerrero 1984: fig. 10, 4; Guerrero 1999: 16, } \\
\text { tipo II.1, fig. 10, 1-2 }\end{array}$ \\
\hline Estrecho & - Lixus & II - I a.C. & Bonet et al. 2005: 137-138 \\
\hline
\end{tabular}

Tabla 5.

\begin{tabular}{|l|l|c|l|}
\hline \multicolumn{1}{|c|}{ Área } & \multicolumn{1}{|c|}{ Yacimientos } & Cronología & \multicolumn{1}{c|}{ Bibliografía } \\
\hline \multirow{3}{*}{ Cerdeña } & - Olbia & III-II a.C. & Amadori et al. 2009: fig. 2, Olb11 \\
\cline { 2 - 4 } & - Tharros & III-II a.C. & Amadori et al. 2004: Fig. 2, 15 y 16 \\
\cline { 2 - 4 } & - el Sinis & III-II a.C. & Del Vais 2014: 117, fig. 11, 28-31 \\
\hline Ibiza & Ibiza & Mitad III a II a.C. & Ramon 2012: 594, fig. 6, 34 \\
\hline $\begin{array}{l}\text { Norte de } \\
\text { Africa }\end{array}$ & Cartago & $\begin{array}{c}\text { 2a mitad III a mitad II } \\
\text { a.C. }\end{array}$ & $\begin{array}{l}\text { Lancel 1987: 105-106, lám. 5, 162a2, a3 y c1; } \\
\text { Bechtold 2014: 102, fig. 6, a }\end{array}$ \\
\hline
\end{tabular}

Forma popular en el mundo púnico del Mediterráneo Central (Morel 1990: 62). Para Del Vais (2007: 177) sería una variante tardía (siglos III-II a.C.) del rolled rim ático.

Tiene dos formatos: uno grande, en Cerdeña con diámetro centrado en $21 / 24 \mathrm{~cm}$ y rdp de $7 / 11$ y en Ibiza de $20 / 22 \mathrm{~cm}$ y rdp de $6,5 / 7$. El formato pequeño tiene entre 8 y $10 \mathrm{~cm}$ de diámetro de borde, tanto en Cerdeña como en Ibiza. Las rdp son de 8,7/10 y 7,5/12 respectivamente.

En Ibiza, Ramon la relaciona con formas de la Campaniense $\mathrm{A}$, documentándola en momentos relativamente tardíos, entre la mitad del siglo II a.C. hasta los inicios del I a.C., aunque quizás pudiese darse algo antes. (Tabla 6)

II-1b: Pátera de paredes tensas, con borde provisto de un engrosamiento o moldura almendrada al interior (fig. 3).

Aproximadamente F-2233g de Morel. Es una forma exclusiva de Cerdeña, con una cronología amplia, de los siglos III-II a.C. (Tabla 7).

II-2: Pátera de paredes tensas algo abombadas, con borde moldurado al interior (fig. 3).

Recuerda a la F-1644/46 de Morel, fechada en el siglo III y la primera mitad del II a.C. Aparece en la cerámica común de Cerdeña como vemos en Monte Sirai. La cronología es poco precisa: siglos III-II a.C. No compartimos la referencia de Del Vais (2007: 177) a formas áticas de barniz negro rilled rim, sino que pensamos que estamos ante otra de las formas típicas púnico-helenísticas del Mediterráneo Central y Occidental.

En Cerdeña los diámetros de borde están entre 20 y $25 \mathrm{~cm}$, y las rdp entre 6 y 7; en Ibiza, entre 18 y $21 \mathrm{~cm}$ y las rdp entre 6,5 y 13 . (Tabla 8 )

II-3: Pátera de inflexión alta y borde recto o ligeramente reentrante (fig. 3). Corresponde a las series F-2252/58 de Morel, o Lamb. 5. En cocción oxidante, escasamente representada en Cerdeña. En Ibiza, los diámetros de borde están entre 22 y $27 \mathrm{~cm}$, y la rdp oscila entre 5,5 y 10.

Forma de cronología baja (segunda mitad del siglo II a mitad del I a.C.), parece una imitación de las de barniz negro itálicas, Campaniense A o Cales Media o Tardía. (Tabla 9)

II-4: Pátera más profunda que las anteriores, con paredes tensas y fuerte carena en el quinto superior de la pared, seguido de una inflexión del borde que es recto o ligeramente vuelto hacia fuera (fig. 3).

Recuerda al tipo F-2263a (Cerdeña) o a la serie F-2632 (Ibiza), que son producciones del Mediterráneo 
Tabla 6.

\begin{tabular}{|c|c|c|c|}
\hline Área & Yacimientos & Cronología & Bibliografía \\
\hline \multirow{7}{*}{ Cerdeña } & - Monte Sirai & $2^{\mathrm{a}}$ III a mitad II a.C. & Campanella 1999: Fábricas 1 y 3, fig. 20 \\
\hline & - Tharros & III-II a.C. & Amadori et al. 2004: fig. 2, 1213 y 14 \\
\hline & - El Sinis & & Del Vais 2014: 117, fig. 11, 25-27 \\
\hline & - Olbia & & Amadori et al. 2009: fig. 2, Olb 18 y Olb 10 \\
\hline & - Cagliari & mitad III a mitad II a.C. & Tronchetti 2001: 284, lám. IV \\
\hline & - Neápolis & & Museo de Oristano \\
\hline & - Pauli Stincus y Truncu e’Molas & & (inéditos) \\
\hline \multirow{3}{*}{ Ibiza } & - Ibiza & mitad II a inicios I a.C. & Ramon 2012: 609, fig. 13, 119-120 \\
\hline & - Can Vicent & $2^{\mathrm{a}}$ mitad II a.C. & $\begin{array}{l}\text { Pérez Ballester y Gómez Bellard 2009: 31-32, } \\
\text { figs. 3, } 4 \text { y } 5\end{array}$ \\
\hline & - Avinguda d'Espanya & III-II a.C. & Duarte 2016: 71-73. fig. 15 \\
\hline \multirow{2}{*}{ Baleares } & - Na Guardis & antes del 130/120 a.C. & Guerrero 1999: fig. 15, tipo II.5b \\
\hline & - Turó de Ses Beies & final II a.C. & Camps y Vallespir 1998:257, fig. 88 \\
\hline $\begin{array}{l}\text { Fachada } \\
\text { Mediterránea }\end{array}$ & - La Albufereta & II a.C. & Bonet y Mata 1988: 20 \\
\hline Estrecho & - Bahía de Cádiz & II a.C. & Niveau 2009: 248, forma III, fig. 7 \\
\hline \multirow{2}{*}{ N. de África } & - Orán & & $\begin{array}{l}\text { Vuillemot 1965: } 348 \text {, sep. } 21 \text {, n.3; Bridoux } \\
\text { 2006: 1662, fig. } 3\end{array}$ \\
\hline & - Cartago & $\begin{array}{l}1^{\text {a }} \text { mitad III a mitad II } \\
\text { a.C. }\end{array}$ & $\begin{array}{l}\text { Bechtold 2014: 99, fig. 5, b; 102, fig. } 6 \text { d; 106, } \\
\text { fig. 7, d, e }\end{array}$ \\
\hline
\end{tabular}

Tabla 7.

\begin{tabular}{|c|l|l|l|}
\hline \multicolumn{1}{|c|}{ Área } & \multicolumn{1}{|c|}{ Yacimientos } & Cronología & \multicolumn{1}{|c|}{ Bibliografía } \\
\hline Cerdeña & - Monte Sirai & III-II a.C. & Campanella 1999: fig. 20 \\
\hline & - Neápolis & III-II a.C. & Museo de Oristano \\
\hline & - Pauli Stincus y Truncu e'Molas & & (inéditos) \\
\hline
\end{tabular}

Occidental (Morel 1981: 195-197). Guerrero no la considera ibicenca.

En Cerdeña, conocemos un posible ejemplar de Pauli Stincus (inédito) de $24 \mathrm{~cm}$ de diámetro de borde y rdp de 3,4 aproximadamente. En Ibiza, los diámetros de borde están entre 20 y $22 \mathrm{~cm}$, y las rdp oscilan entre 3,3 y 3,6 , relativamente profundas. No aparece fuera de las islas. La cronología en Ibiza está centrada en la segunda mitad del siglo II a.C. (Tabla 10).
II-5: Patera de inflexión alta y borde recto y exvasado (fig. 3).

Similar a las series F-2271/73 y F-2277 de Morel (también Lamb. 5/7). Los prototipos parecen claramente de producciones etruscas de barniz negro del siglo I a.C. de cronología tardía (Morel 1981: 159-160).

En Cerdeña y en Ibiza encontramos piezas de gran diámetro $(26 \mathrm{~cm})$. Las rdp son diferentes: 7,5 en 


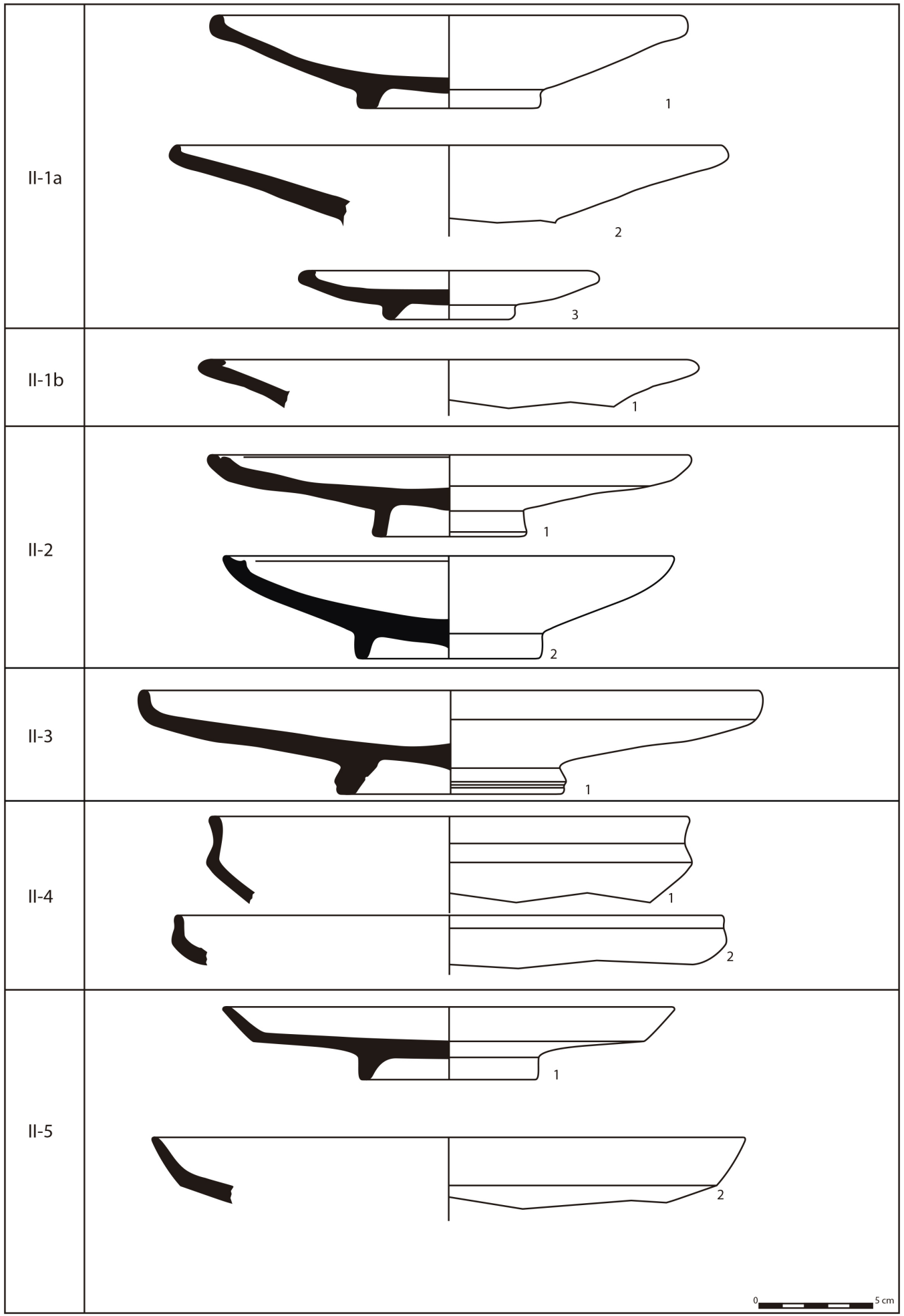

Figura 3. II-1a. 1: Na Guardis (Mallorca). 2: Pauli Stincus. 3: Na Guardis (Mallorca). II-1b. 1: Pauli Stincus. II-2. 1: Na Guardis (Mallorca). 2: Olbia. II-3. 1: Ibiza, Cap des Llibrell. II-4. 1: Ibiza, Can Vicent d'en Jaume. 2: Pauli Stincus. II-5. 1: Ibiza, Puig des Molins. 2: Pauli Stincus. 
Tabla 8 .

\begin{tabular}{|l|l|c|l|}
\hline \multicolumn{1}{|c|}{ Área } & \multicolumn{1}{|c|}{ Yacimientos } & Cronología & \multicolumn{1}{c|}{ Bibliografía } \\
\hline \multirow{4}{*}{ Cerdeña } & - Monte Sirai & III-II a.C. & Campanella 1999: 48-49, fig. 6 \\
\cline { 2 - 4 } & - Olbia & III-II a.C. & Amadori et al. 2009: fig. 2, Olb 9 \\
\cline { 2 - 4 } & - Pauli Stincus y Truncu e'Molas & & (inéditos) \\
\hline \multirow{2}{*}{ Ibiza } & - Ses Figueretes & $225-210$ a.C. & Ramon 1997: 26-28, fig.14, 91 \\
\cline { 2 - 4 } & - Can Vicent & $2^{\text {a } \text { mitad II a.C. }}$ & Pérez Ballester y Gómez Bellard 2009: 36, fig. 6 \\
\hline Baleares & - Na Guardis & 250-225 a mitad II a.C. & Guerrero 1999: fig. 16, tipo II.6 \\
\hline
\end{tabular}

Tabla 9.

\begin{tabular}{|l|l|c|l|}
\hline \multicolumn{1}{|c|}{ Área } & \multicolumn{1}{|c|}{ Yacimientos } & Cronología & \multicolumn{1}{c|}{ Bibliografía } \\
\hline Ibiza & - S'Olivar d'es Mallorquí & Mitad II a.C. & Gómez Bellard 1995 \\
\hline & - Cap Llibrell & Inicios I a.C. & Ramon 2012: 609, fig. 13, 116-117 \\
\hline Cerdeña & - Truncu e'Molas & & Inédito \\
\hline $\begin{array}{l}\text { Fachada } \\
\text { Mediterránea }\end{array}$ & - Cartagena & Finales II a.C. & Anfiteatro inéditos (2 ejs.) \\
\hline Estrecho & - Lixus & II - I a.C. & Bonet et al. 2005: 137-138 \\
\hline
\end{tabular}

Tabla 10.

\begin{tabular}{|l|l|c|l|}
\hline \multicolumn{1}{|c|}{ Área } & \multicolumn{1}{|c|}{ Yacimientos } & Cronología & \multicolumn{1}{c|}{ Bibliografía } \\
\hline Cerdeña & - Pauli Stincus y Truncu e'Molas & & (inédito) \\
\hline \multirow{3}{*}{ Ibiza } & - Hort d'en Xim & $2^{\text {a mitad II a.C. }}$ & Ramon 1994: 49-50, fig. 10, no55 \\
\cline { 2 - 4 } & - Can Vicent & No datada & $\begin{array}{l}\text { Pérez Ballester y Gómez Bellard 2009: 36-37, } \\
\text { fig. 6 }\end{array}$ \\
\cline { 2 - 4 } & - Avinguda d'Espanya & III-II a.C. & Duarte 2016: 73, fig. 16 \\
\hline \multirow{3}{*}{ Baleares } & - Na Guardis & $\begin{array}{r}2^{\text {a }} \text { mitad III a 130/120 } \\
\text { a.C. }\end{array}$ & Guerrero 1999: 22, fig. 30. \\
\cline { 2 - 4 } & - Turó de Ses Beies & Finales II a.C. & Camps y Vallespir 1998: 74, fig.16 \\
\hline
\end{tabular}

Tabla 11.

\begin{tabular}{|l|l|c|l|}
\hline \multicolumn{1}{|c|}{ Área } & \multicolumn{1}{|c|}{ Yacimientos } & Cronología & \multicolumn{1}{c|}{ Bibliografía } \\
\hline \multirow{2}{*}{ Cerdeña } & - Sulkis & Fin II a I a.C. & $\begin{array}{l}\text { Morel 1963: 25; 1981: 160; Tronchetti 1996: } \\
\text { fig. 4 }\end{array}$ \\
\cline { 2 - 5 } & - Pauli Stincus & & Inédito \\
\hline Ibiza & - Puig des Molins & Fin II a I a.C. & Ramon 2012: 609, fig. 13, 118 \\
\hline Estrecho & - Lixus & II-I a.C. & Bonet et al. 2005: 137-138 \\
\hline
\end{tabular}


Tabla 12.

\begin{tabular}{|c|c|c|c|}
\hline Área & Yacimientos & Cronología & Bibliografía \\
\hline Cerdeña & Pauli Stincus y Truncu'e Molas & & Inéditos \\
\hline \multirow{2}{*}{ Ibiza } & $\begin{array}{l}\text { - Can'Eloi, Avinguda d'Espanya } \\
3 \text { y Hort d'en Xim }\end{array}$ & II a inicios I a.C. & $\begin{array}{l}\text { Ramon 2012: 609, fig. 13, 127; Duarte 2016: } \\
\text { 75-76, fig. } 17\end{array}$ \\
\hline & - Can Vicent & $2^{\mathrm{a}} \operatorname{mitad}$ II a.C. & $\begin{array}{l}\text { Pérez Ballester y Gómez Bellard 2009: 39-40, } \\
\text { figs. } 7 \text { y } 8\end{array}$ \\
\hline \multirow{4}{*}{ Baleares } & - Na Guardis y Es Trenc & $1^{\mathrm{a}}$ mitad II a.C. & Guerrero 1998: 181-184 \\
\hline & - Turó de Ses Beies & finales II a.C. & Camps y Vallespir 1998: figs. 24, 28, 33, 45 \\
\hline & - Cales Coves & & $\begin{array}{l}\text { Fernández Miranda y Belén 1977: figs. 10, } 10 \\
\text { y } 13\end{array}$ \\
\hline & - Sa Punta des Patró & & Hernández y Sanmartí 2003: 92, fig. 4, 10 \\
\hline \multirow{2}{*}{$\begin{array}{l}\text { Fachada } \\
\text { Mediterránea }\end{array}$} & $\begin{array}{l}\text { - Tossal de S. Miquel y La Al- } \\
\text { bufereta }\end{array}$ & & $\begin{array}{l}\text { Bonet y Mata 1988: 19-20; Bonet 1996: 391, } \\
\text { figs. } 68 \text { y } 120\end{array}$ \\
\hline & - La Malladeta & & Rouillard et al. 2014 : 109, fig. 118 \\
\hline Estrecho & - Lixus & II-I a.C. & Bonet et al. 2005: 137-138 \\
\hline N. de África & - Cartago & $1^{\mathrm{a}}$ mitad II a.C. & Bechtold 2014: 106, fig. 8, o \\
\hline
\end{tabular}

Cerdeña, y 11,6 en Ibiza. Las de Cerdeña son en cocción reductora, en la clase "Gris Sarda". (Tabla 11)

III: Cuenco profundo (It: coppa; Fr: bol; Ingl: bowl).

Formas abiertas y profundas de borde generalmente no exvasado. El diámetro del borde varía entre 10 y 16 $\mathrm{cm}$, con excepciones que llegan a $20 \mathrm{~cm}$. La rdp se corresponde con recipientes profundos: 1 a 3 , estando la mayoría entre 1,5-2.

III-1: Cuenco profundo de borde algo reentrante y paredes ligeramente curvadas. (fig. 4).

Recuerda a la serie F-2978 de la clasificación de Morel, o a la más genérica Lamb. 31, típica de la Campaniense A desde el último cuarto del siglo III a la primera mitad del I a.C.

Es escasa en Cerdeña (posibles ejemplares en Truncu'e Molas y Pauli Stincus), y está presente en Ibiza, con diámetros de 13 a $16 \mathrm{~cm}$ y rdp entre 2,3 y 2,7. (Tabla 12).

III-2: Cuenco profundo abierto de paredes tensas y borde ligeramente moldurado al exterior, similar a los de la serie F-2573 de Morel (fig. 4).

Se caracteriza por la presencia de dos surcos paralelos por el exterior, bajo el borde. Se fecharían hacia la $1^{\text {a }}$ mitad del siglo II a.C. No la documentamos en Cerdeña. (Tabla 13).

III-3: Cuenco profundo abierto de paredes tensas, con surcos o molduras por el interior del borde (fig. 4).

Si fueran de barniz negro, entrarían en la F-2153/54 de Morel, que agrupa a vasos ápodos o con pseudopie, con cronología de fines del siglo III o primera mitad del II a.C.

Solo hemos registrado un fragmento en Cerdeña, concretamente en Neápolis, con $14 \mathrm{~cm}$ de diámetro de borde y rdp indeterminada. (Tabla 14).

III-4: Gran cuenco profundo de borde reentrante (fig. 4).

Conocido también como "urna" o "cuenco de aspecto cónico", es una forma que recuerda a las sítulas de la especie F-6520 de Morel, aunque la nuestra carece de asa superior o de estribo. De hecho, Guerrero (1999: 30 , fig. 44) lo incluye entre la vajilla doméstica aunque reconoce que podría pertenecer al ajuar de mesa.

Característico de Ibiza, no se encuentra en Cerdeña. Aparece entre la mitad del siglo III y la segunda mitad del II a.C. Las medidas de las piezas completas que conocemos son de distinto formato: una de Cales Coves (Menorca) tiene $17 \mathrm{~cm}$ de altura, $20 \mathrm{~cm}$ de diámetro de borde y rdp de 1,3; otra de Cala Vedella (Ibiza) 
Tabla 13.

\begin{tabular}{|l|l|c|l|}
\hline \multicolumn{1}{|c|}{ Área } & \multicolumn{1}{|c|}{ Yacimientos } & Cronología & \multicolumn{1}{c|}{ Bibliografía } \\
\hline Ibiza & - Can Vicent & $2^{\text {a }}$ mitad II a.C. & Pérez Ballester y Gómez Bellard 2009: 43, fig. 9 \\
\hline Baleares & - Na Guardis & II hasta 130/120 a.C. & Guerrero 1984: fig. 54; 1999: tipo I.1, fig. 22 \\
\hline
\end{tabular}

Tabla 14.

\begin{tabular}{|c|l|c|l|}
\hline Área & \multicolumn{1}{|c|}{ Yacimientos } & Cronología & \multicolumn{1}{c|}{ Bibliografía } \\
\hline Cerdeña & - Neápolis & Finales III a 1 ${ }^{\mathrm{a}}$ mitad II a.C. & Museo de Oristano \\
\hline
\end{tabular}

Tabla 15

\begin{tabular}{|c|c|c|c|}
\hline Área & Yacimientos & Cronología & Bibliografía \\
\hline \multirow{6}{*}{ Ibiza } & - Taller AE-20 & IV a mitad III a.C. & Ramon 1998b:171, fig.11, sin engobe \\
\hline & - Ses Figueretes & $2^{\mathrm{a}} \operatorname{mitad}$ III a.C. & Ramon 1997: 17-19, figs. 5 y 6 \\
\hline & - Dep. AR-33V & mitad III a II a.C. & Ramon 1998a: 162-163; Ramon 2012: 594, fig. 6, 40 \\
\hline & - Can Vicent & $2^{\mathrm{a}}$ mitad II a.C. & Pérez Ballester y Gómez Bellard 2009: 45-46, fig. 13 \\
\hline & -Avinguda d'Espanya & III-II a.C. & Duarte 2016: 75-76, fig. 18 \\
\hline & - Cala Vedella & & Tarradell y Font 2000: 74, CV-11 \\
\hline \multirow{3}{*}{ Baleares } & - Na Guardis y fondeadero & II hasta $130 / 120$ a.C. & Guerrero 1999 \\
\hline & - Turó de Ses Beies & finales II a.C. & Camps y Vallespir 1998: 257, fig.88 \\
\hline & - Cales Coves & & $\begin{array}{l}\text { Fernández Miranda y Belén 1977: fig.15; Belén y Fer- } \\
\text { nández Miranda 1979: fig.29 }\end{array}$ \\
\hline $\begin{array}{l}\text { Fachada } \\
\text { Mediterránea }\end{array}$ & - La Malladeta & & Rouillard et al. 2014:109 \\
\hline
\end{tabular}

tiene $14 \mathrm{~cm}$ de altura, diámetro de borde de $14 \mathrm{~cm}$ y rdp de 1. (Tabla 15)

IV: Cuenco poco profundo (It: copa, ciottola; Fr: bol, écuelle; Ingl: bowl).

Formas de borde no exvasado a menudo claramente reentrante, de paredes curvadas o abombadas, casi todas dentro de la categoría F-2000 de Morel. La rdp oscila entre 2,5 y 3,5 , y los diámetros entre 6 y $15 \mathrm{~cm}$, aunque pueden llegar a $20 \mathrm{~cm}$.

IV-1a: Cuenco poco profundo de paredes tensas y curvadas y borde reentrante (fig. 5).

Similar a las formas 26 y 27 a y b de Lamboglia o a las especies F-2760 y F-2780 de Morel. Guerrero la denominó "F-26/27" por el parecido con las de barniz negro de la clasificación de Lamboglia. Ramon (1997: 19-21) ve su inspiración en prototipos púnicos. Para nosotros, tanto los cuencos de Ibiza, Cerdeña o los de Cartago y Kuass (Niveau 2009: 251 y 255, Forma X) tienen un mismo prototipo mediterráneo, del que participan igualmente las cerámicas de barniz negro de “pequeñas estampillas", la Campaniense A, Talleres Occidentales catalanes, o incluso las cerámicas engobadas de pasta clara marsellesas (Bats 1993: CL-MAS 237), producciones centradas en los siglos III y II a.C. En resumen, estamos ante otra forma "panmediterránea”, como afirmaba Guerrero (1999: 12, Fig. 4a ). Ramon (1997: 19-21) distingue un grupo de cuencos de mayores dimensiones vinculado a la Lamb. 26 (aprox. 


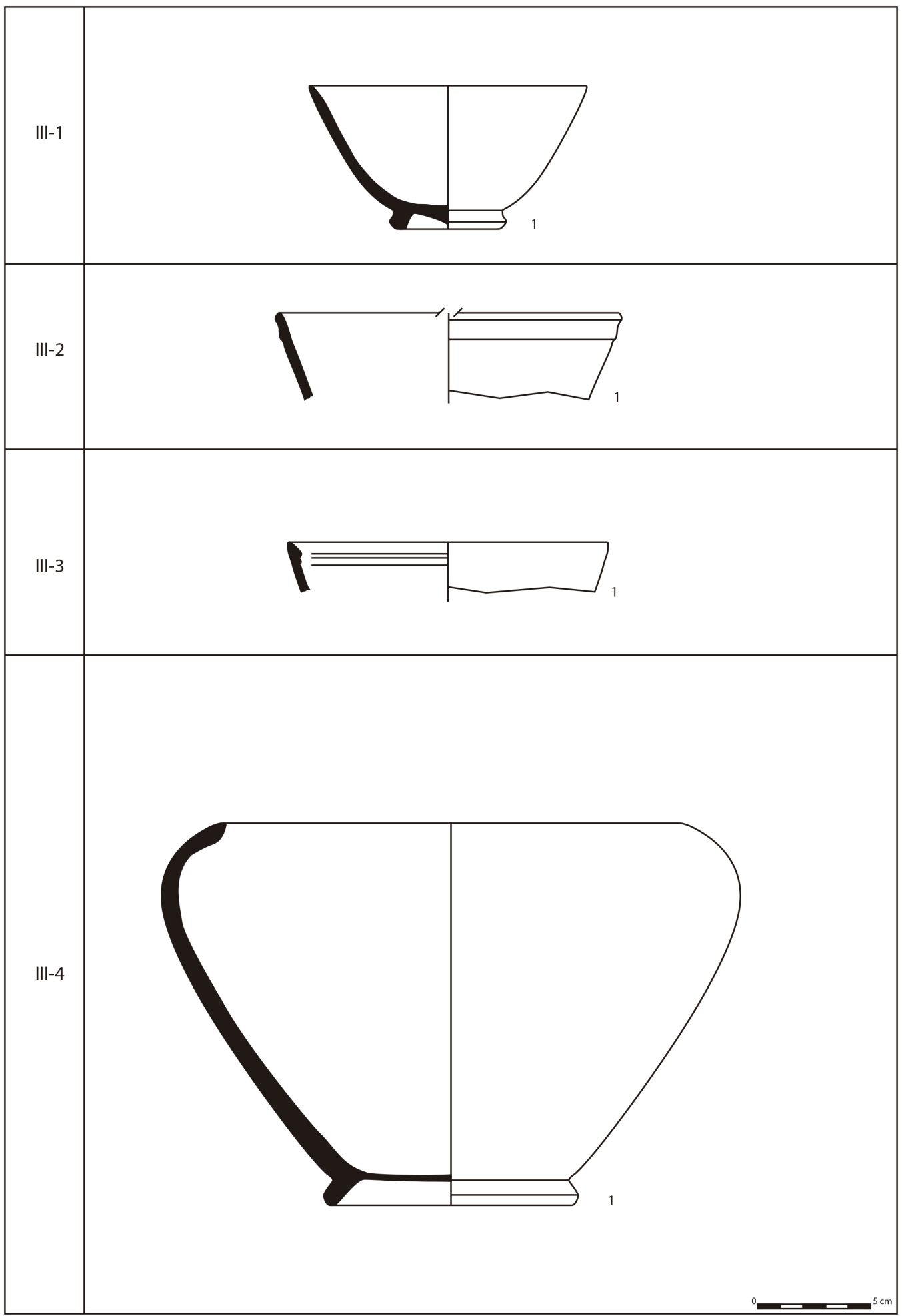

Figura 4. III-1. 1: Na Guardis (Mallorca). III-2. 1: Ibiza, Can Vicent d'en Jaume. III-3. 1: Neapolis. III-4. 1: Cales Coves (Menorca). 
Tabla 16 .

\begin{tabular}{|c|c|c|c|}
\hline Área & Yacimientos & Cronología & Bibliografía \\
\hline \multirow{6}{*}{ Cerdeña } & - Cagliari & $\begin{array}{l}2^{\mathrm{a}} \text { mitad III a } 1^{\mathrm{a}} \text { mitad } \\
\text { II a.C. }\end{array}$ & Tronchetti 2001: 283 y láms. III y V \\
\hline & - Monte Sirai & III-II a.C. & Campanella 1999: fig. 22 \\
\hline & - Tharros & III-II a.C. & Amadori et al. 2004: fig. 1, 1 a 3 \\
\hline & - El Sinis & & Del Vais 2014: 117, fig. 11, 15-18 \\
\hline & - Olbia & III-II a.C. & Amadori et al. 2009: fig. 1, Olb 2 \\
\hline & - Pauli Stincus y Truncu e'Molas & & (inéditas) \\
\hline \multirow{6}{*}{ Ibiza } & $\begin{array}{l}\text { - Ses Figueretes, AR-33/V, Hort } \\
\text { del Xim }\end{array}$ & $2^{\mathrm{a}}$ mitad III a.C. & Ramon 2012: 596, fig. 6, 45 a 47; 1997: 19-21. \\
\hline & - Avinguda d'Espanya & II a.C. & Duarte 2016: 76-80, figs. 19-21 \\
\hline & - Can Vicent & $2^{\mathrm{a}}$ mitad II a.C. & $\begin{array}{l}\text { Pérez Ballester y Gómez Bellard 2009: 46-48, } \\
\text { figs. 10-11 }\end{array}$ \\
\hline & - S'Olivar d'Es Mallorquí & $1^{\mathrm{a}}$ mitad II a.C. & Gómez Bellard 1995: 155-156, 28 y 33 \\
\hline & $\begin{array}{l}\text { - Cala d'Hort, Cala Vedella y } \\
\text { Cala Tarida }\end{array}$ & III-II a.C. & Tarradell y Font 2000: 58, 73 y 90 \\
\hline & - Illa des Conills & & Pons 2005: fig. 14, 2 y 3 \\
\hline \multirow{4}{*}{ Baleares } & - Na Guardis & $\begin{array}{l}\text { 300/225 a.C. a } 130 / 120 \\
\text { a.C. } \\
\end{array}$ & Guerrero 1998: 184-190 \\
\hline & - Turó de Ses Beies & finales II a 123-100 a.C. & Camps y Vallespir 1998: 257, fig.88 \\
\hline & - Sa Punta de Patró & & Hernández y Sanmartí 2003: 92, fig. 4, 11 \\
\hline & - Cales Coves & & $\begin{array}{l}\text { Belén y Fernández Miranda 1979: figs. 16, } 11 \\
\text { y } 12\end{array}$ \\
\hline \multirow{3}{*}{$\begin{array}{l}\text { Fachada } \\
\text { Mediterránea }\end{array}$} & - Cartagena & $\begin{array}{l}\text { Último tercio III a } \\
\text { 130/120 a.C. }\end{array}$ & $\begin{array}{l}\text { Pérez Ballester y Berrocal 2010: 118, fig. 6; } \\
\text { Ruiz Valderas 2000; Martín Camino 1998: 13, } \\
\text { lám. IV }\end{array}$ \\
\hline & - La Malladeta & & Rouillard et al. 2014: 109, fig. 118 \\
\hline & - Alorda Park & & Principal 1998: 66-70 \\
\hline \multirow{2}{*}{ Estrecho } & - Bahía de Cádiz & III a II a.C. & Niveau 2003: 148, forma X \\
\hline & - Lixus - Kuass & III a mitad II a.C. & Bonet et al. 2005: 135-137 \\
\hline N. de Africa & - Cartago & $\begin{array}{l}1^{\mathrm{a}} \text { mitad III a mitad II } \\
\text { a.C. }\end{array}$ & $\begin{array}{l}\text { Bechtold 2014: 99, fig. 5, g; 106, fig. 8, n; Lan- } \\
\text { cel 1978:108, lám. 9, } 273 \text { a2 y a4 }\end{array}$ \\
\hline
\end{tabular}

F-2762) y otro vinculado a la Lamb. 27a/b (aprox. F-2784). Su cronología es amplia: desde la mitad del siglo III a la segunda mitad del II a.C.

Es frecuente en Cerdeña, donde los diámetros de borde se concentran entre 14 y $16 \mathrm{~cm}$, con rdp variable entre 2,4 y 4,3. En Ibiza, donde también es abundante, tiene dos formatos: $13-14 \mathrm{~cm}$, y $18-20 \mathrm{~cm}$ de diámetro de borde. La rdp oscila entre 2,5 y 3,7. Hay un precedente ( $1^{\mathrm{a}} \mathrm{mitad}$ del siglo III a.C.) tanto en cocción oxidante con reductora, en unas páteras profundas del taller AE-20 (Ramon 1998b: 172). (Tabla 16) 
Tabla 17.

\begin{tabular}{|c|c|c|c|}
\hline Área & Yacimientos & Cronología & Bibliografía \\
\hline \multirow{6}{*}{ Cerdeña } & - Cagliari & III a mitad II a.C. & Tronchetti 2001: 283 y 287, lám. III y VII \\
\hline & - Monte Sirai & III a mitad II a.C. & Campanella 1999 \\
\hline & - Tharros & III a mitad II a.C. & Amadori et al. 2004: fig. 2, 8 y 9 \\
\hline & - El Sinis & III a mitad II a.C. & Del Vais 2014: 117, fig. 11, 19-22 \\
\hline & - Olbia & III a mitad II a.C. & Amadori et al. 2009: fig. 1, Olb 8; fig. 2, Olb 13 \\
\hline & - Pauli Stincus y Truncu e'Molas & & (Inéditos) \\
\hline \multirow{2}{*}{ Ibiza } & -Ibiza & $2^{\mathrm{a}}$ mitad del III a.C. & Ramon 2012: 596, fig. 7, 53 \\
\hline & -Avinguda d'Espanya & Sin datar & Duarte 2016: 80, fig. 22 \\
\hline Baleares & - Mallorca & Finales IV a III a.C. & Guerrero 1999: 11, fig. 3, tipo I.2a \\
\hline \multirow{2}{*}{ Estrecho } & - Bahía de Cádiz & $\begin{array}{c}\text { Finales IV a inicios II } \\
\text { a.C. }\end{array}$ & Niveau 2009: 248 y 255 , figs. 16 y 17 , forma IX \\
\hline & - Kuass - Lixus & III a mitad II a.C. & $\begin{array}{l}\text { Bonet et al. 2005: 135-137 } \\
\text { Kebir Alahui 2007: forma } 4\end{array}$ \\
\hline N. de África & - Cartago & III a.C. & Bechtold 2014: 99-100, fig. 5, e; 102, fig. 6, h,i \\
\hline
\end{tabular}

$I V-1 b$ : Pequeños cuencos o copitas poco profundas de borde reentrante (fig. 5).

Corresponden con bastante exactitud a las formas 25 y 21/25 de Lamboglia, y F-2765 y F-2711 de Morel. Para Del Vais (2007) es una de las formas más comunes de la vajilla de mesa del mundo púnico-helenístico, incluída Cartago. Las copitas semejantes a la Lamb. 21/25 derivarían claramente de la forma ática small bowl-broad base, con el típico pie ancho ligeramente biselado; las que referimos a la Lamb. 25, con pie de anillo simple, son algo más profundas y se asemejan a otras áticas como el saltcellar footed.

En Cerdeña los diámetros de las Lamb. 21/25 están entre 7 y $8 \mathrm{~cm}$, con rdp de 5; las Lamb. 25 tienen diámetros entre 8 y $10 \mathrm{~cm}$, y rdp de 2,6/3, más profundas. Se documentan prácticamente en todos los yacimientos consultados. Perdura en el tiempo, encontrándose en todo el siglo III y hasta la mitad del II a.C.

En Ibiza son más raras y se centran cronológicamente en el siglo III a.C. Las Lamb. 21/25 tienen diámetros de $8 \mathrm{~cm}$ y rdp como las de Cerdeña; las Lamb. 25 , son algo menores: sobre $7 \mathrm{~cm}$ y misma rdp que Cerdeña.

Como veremos, en Cádiz y Kuass es la forma más frecuente junto a los platos de pescado. (Tabla 17)
IV-2: Pequeño cuenco poco profundo con fuerte inflexión o carena cerca del borde, que es reentrante (fig. 5).

Similar a la forma Lamb 34 (F-2733/37 de Morel). Escasamente representada tanto en Cerdeña como en Ibiza. En las dos islas, es una forma que se documenta a finales del siglo III y hasta la mitad del II a.C., cronología concordante con la misma forma en la Campaniense A. En Cerdeña, los diámetros están alrededor de $8 \mathrm{~cm}$, y una rdp de 3; en Ibiza son algo más pequeñas, de $6-7 \mathrm{~cm}$ y rdp de 3,8 . (Tabla 18)

IV-3: Cuenco poco profundo de borde reentrante con surcos al exterior, junto al borde (fig. 5).

Aproximadamente de la especie F- 2560 de Morel. Solo conocemos parte de un ejemplar, procedente de Cerdeña, concretamente de Neápolis (Museo de Oristano) con un diámetro de borde de $14 \mathrm{~cm}$ y rdp indeterminada. (Tabla 19)

V: Cuenco ancho poco profundo (It: coppa; Fr: bol; Ingl: bowl).

Reúne formas de paredes rectilíneas o ligeramente curvadas, abiertas, de borde exvasado, en algún caso con borde reentrante. Corresponden fundamentalmente a los géneros F-2600, F-2800 y F-2900 de Morel. Los diámetros de borde están entre 16 y $20 \mathrm{~cm}$ pero también los hay mayores; la rdp se sitúa entre 3,5 y 4,5. 
Tabla 18

\begin{tabular}{|l|l|c|l|}
\hline \multicolumn{1}{|c|}{ Área } & \multicolumn{1}{|c|}{ Yacimientos } & Cronología & \multicolumn{1}{c|}{ Bibliografía } \\
\hline Cerdeña & - Cagliari & Finales III a 1 ${ }^{a}$ mitad II a.C. & Tronchetti 2001: 283, lám.IV \\
\hline Ibiza & Ibiza & $2^{\text {a }}$ mitad del III a.C. a 1 ${ }^{a}$ mitad II a.C. & Ramon 2012: 596, fig. 7, 54 \\
\hline Baleares & - Na Guardis y Cales Coves & $2^{\text {a }}$ mitad III a 130/120 a.C. & Guerrero 1999: fig. 3, 1 y 3, tipo I.2a \\
\hline $\begin{array}{l}\text { Fachada } \\
\text { mediterránea }\end{array}$ & - La Madalleta & & Rouillard et al. 2014: 109, fig. 118, 14). \\
\hline N. de África & - Cartago & $1^{\text {a } m i t a d ~ I I ~ a . C . ~}$ & Bechtold 2014: 106, fig. 8, m \\
\hline
\end{tabular}

Tabla 19.

\begin{tabular}{|c|l|l|l|}
\hline Área & \multicolumn{1}{|c|}{ Yacimientos } & \multicolumn{1}{c|}{ Cronología } & \multicolumn{1}{c|}{ Bibliografía } \\
\hline Cerdeña & - Neápolis & & Museo de Oristano \\
\hline
\end{tabular}

V-1a: Cuenco ancho poco profundo, de paredes rectilíneas con inflexión suave en el tercio superior y borde recto o ligeramente reentrante (fig. 6).

Esta forma no se relaciona directamente con otras de barniz negro. Como la IV-1b, sí la vemos entre la cerámica común de Cartago, en pastas grises y oxidadas y engobadas, con cronología de primera mitad del siglo II a.C. (Lancel 1987: tipos 212a3 y 212b1, 107 108, lám.8). También en cerámicas engobadas de pasta clara massaliotas de cronología algo más antigua (Bats 1993: 207, CL-MAS 220a). Estaríamos ante un vaso muy común en el Mediterráneo Central y Occidental, sin que sea factible determinar si hubo un prototipo concreto; de haberlo, seguramente sería fenicio, como opina Guerrero (1999: 14-15) con paralelos en Trayamar, Mogador, Toscanos, etc. En Cerdeña e Ibiza, se documenta desde la mitad del siglo III a.C.

En Cerdeña los diámetros de borde oscilan entre 16,5 y $20,5 \mathrm{~cm}$ y las rdp son de 2,4/4,2. En Ibiza hay un formato semejante: diámetros de borde de $18-24 \mathrm{~cm}$ y rdp de 2,1/3,3, quizás algo más profundos que los sardos. (Tabla 20)

$V$-1b: Cuenco ancho poco profundo, de pared rectilinea y carena viva en el tercio superior de la misma. Borde recto o ligeramente reentrante (fig. 6).

Parece obedecer a una evolución desde los cuencos de inflexión suave V-1a (Ramon 1994: 49). Siempre se fabrica en cocción oxidante. Su cronología coincide en el siglo III con la de los cuencos V-1a, aunque luego perdura hasta inicios del I a.C., al menos en Ibiza.
En Cerdeña son escasos, y a menudo se confunden con la V-1a. Hemos podido medir algún diámetro de borde, de $24 \mathrm{~cm}$. En Ibiza es más frecuente, con diámetros de $17-20 \mathrm{~cm}$, llegando en algún caso a los $26 \mathrm{~cm}$. Las rdp están entre 2,4 y 2,6. (Tabla 21)

$V$-2a: Cuenco ancho poco profundo, con inflexión en la parte media de la pared que es exvasada pero con tendencia a la vertical; el extremo del borde tiene un engrosamiento al exterior (fig. 7).

Es semejante a la forma Lamb. 22, F-2681/86 de Morel y outturned rim de la cerámica ática de barniz negro del Ágora de Atenas.

Para Del Vais (2007: 174-175) es una de las formas más representativas de esta vajilla en Cerdeña, aunque distingue las de pared en curva continua tendente a la vertical, más fiel al modelo ático del siglo IV, y otra de pared exvasada y carena media más o menos marcada. Ésta última es nuestra V-2b. En Ibiza es rara.

En Cerdeña aparecen con dos formatos: $12-14 \mathrm{~cm}$ y $17-18 \mathrm{~cm}$ de diámetro de borde y una rdp que varía mucho, entre 2,7 y 5,6. En Ibiza solo hay un formato, de $18-20 \mathrm{~cm}$ y una rdp más constante: 4 .

En la bahía de Cádiz es frecuente (Forma VIII), pero con un formato pequeño: entre 8 y $11 \mathrm{~cm}$ de diámetro de borde. (Tabla 22)

$V$-2b: Cuenco ancho poco profundo, con carena en la parte media-baja de la pared que es claramente exvasada; el extremo del borde tiene un engrosamiento apuntado o redondeado al exterior (fig. 7). 


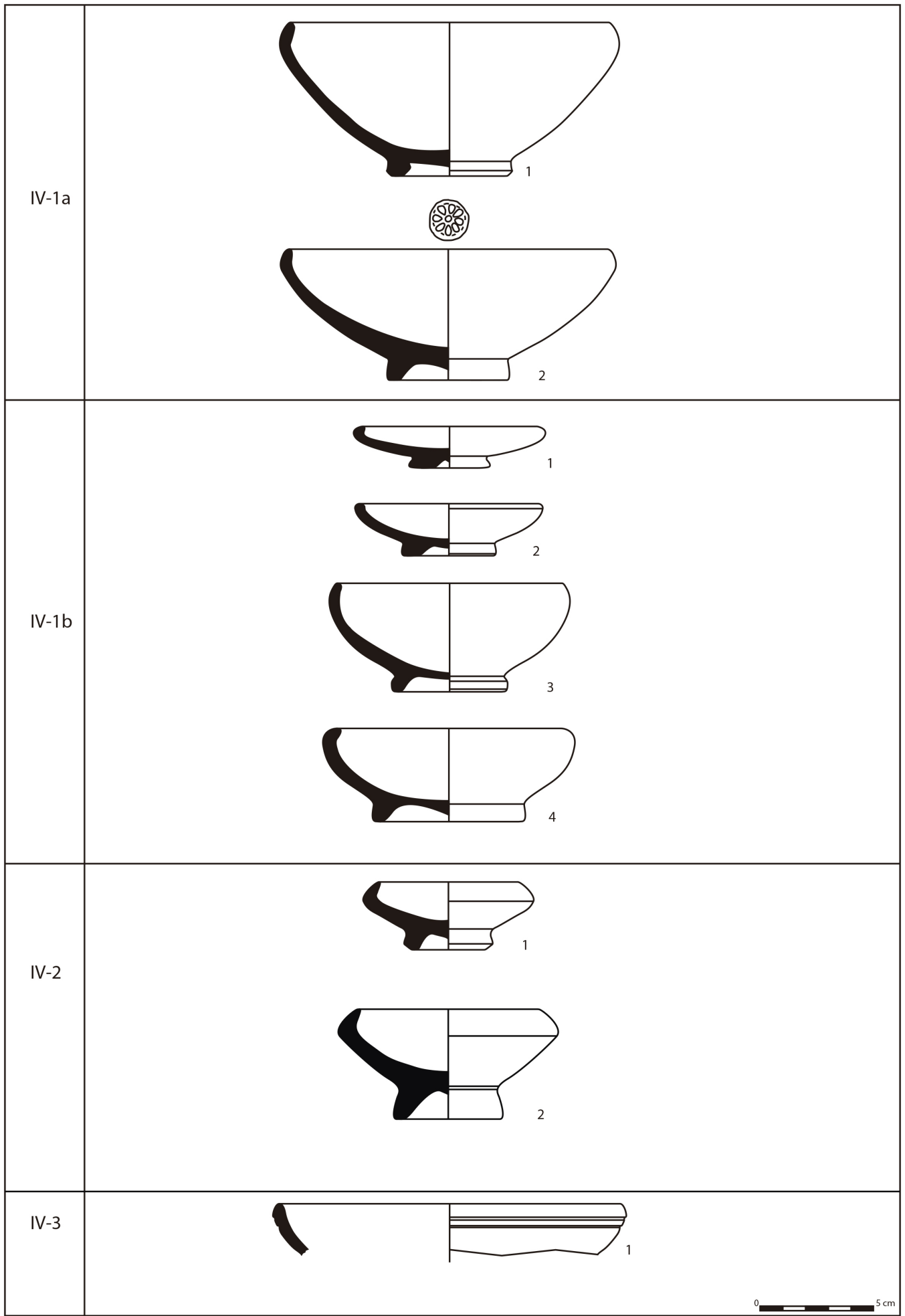

Figura 5. IV-1a. 1: Na Guardis (Mallorca). 2: Cagliari, Cisterna della Cittadella. IV-1b. 1: Na Guardis (Mallorca). 2: Cagliari, Cisterna della Cittadella. 3: Cagliari, Tomba della Bonaria. 4: Cales Coves (Menorca). IV-2. 1: Na Guardis (Mallorca). 2: Cagliari, Tomba della Bonaria. IV-3. 1: Neapolis. 
Tabla 20.

\begin{tabular}{|c|c|c|c|}
\hline Área & Yacimientos & Cronología & Bibliografía \\
\hline \multirow{5}{*}{ Cerdeña } & - Monte Sirai & III a II a.C. & Campanella 1999: fig. 23, no 190 \\
\hline & - Cagliari & $\begin{array}{l}\text { Finales III a } 1^{\mathrm{a}} \mathrm{mitad} \\
\text { II a.C. }\end{array}$ & Tronchetti 2001: lám. VI, 4 \\
\hline & - El Sinis & & Del Vais 2014: 117, fig. 11, 23 \\
\hline & - Olbia & & Amadori et al. 2009: fig. 1, Olb 1 \\
\hline & - Pauli Stincus y Truncu e'Molas & & (inéditos) \\
\hline \multirow{2}{*}{ Ibiza } & $\begin{array}{l}\text { - AR-33, Hort d'en Xim, Ses Fi- } \\
\text { gueretes }\end{array}$ & Mitad III a II a.C. & Ramon 2012: 596, fig. 6, 43 y 44 \\
\hline & - Can Vicent & $2^{\mathrm{a}}$ mitad s. II a.C. & $\begin{array}{l}\text { Pérez Ballester y Gómez Bellard 2009: 51-53, } \\
\text { fig. } 12\end{array}$ \\
\hline Baleares & - Na Guardis & 230 a 190 a.C. & Guerrero 1998: 186 \\
\hline \multirow[t]{2}{*}{$\begin{array}{l}\text { Fachada } \\
\text { mediterránea }\end{array}$} & - Cartagena & $\begin{array}{l}\text { Finales III a } 1^{\mathrm{a}} \text { mitad } \\
\text { II a.C. }\end{array}$ & $\begin{array}{l}\text { Pérez Ballester 1995: 345; Pérez Ballester y Be- } \\
\text { rrocal 2010: 117, fig. 6; Ruiz Valderas 2000; } \\
\text { Martín Camino 1998: 13, lám. IV }\end{array}$ \\
\hline & - La Malladeta & & Rouillard et al. 2014: 109, fig. 118 \\
\hline Estrecho & - Kuass & & Kbiri Alaoui 2007: 180-181, fig. 150 \\
\hline
\end{tabular}

Tabla 21.

\begin{tabular}{|c|c|c|c|}
\hline Área & Yacimientos & Cronología & Bibliografía \\
\hline Cerdeña & - Pauli Stincus y Truncu e'Molas & & (inéditos) \\
\hline \multirow[t]{4}{*}{ Ibiza } & - Ibiza & II a.C. & Ramon 2012: 609, fig. 13, 129 \\
\hline & - Avinguda d'Espanya & antes del 120 a.C. & Duarte 2016: 81, figs. 23-26 \\
\hline & - Can Vicent & $2^{\mathrm{a}}$ mitad II a.C. & $\begin{array}{l}\text { Pérez Ballester y Gómez Bellard 2009: 51-53, } \\
\text { fig. } 12\end{array}$ \\
\hline & - Illa des Conills & fin III a mitad II a.C. & Pons 2005: fig. 14, 1 \\
\hline \multirow[t]{3}{*}{ Baleares } & - Na Guardis & $\begin{array}{l}2^{\mathrm{a}} \text { mitad III a } 130 / 120 \\
\text { a.C. }\end{array}$ & Guerrero 1999: fig. 8, 1 y 3, p.14-15 \\
\hline & - Turó de Ses Beies & II a mitad I a.C. & Camps y Vallespir 1998: figs. 24, 33, 45, 70 \\
\hline & - Cales Coves & & $\begin{array}{l}\text { Belén y Fernández Miranda 1979: 47-51, figs } \\
19 \text { y } 20\end{array}$ \\
\hline $\begin{array}{l}\text { Fachada } \\
\text { mediterránea }\end{array}$ & - Cartagena & $\begin{array}{l}\text { Último tercio III a fines } \\
\text { II a.C. }\end{array}$ & $\begin{array}{l}\text { Pérez Ballester 1995: 345; Pérez Ballester y Be- } \\
\text { rrocal 2010: 117, fig. 6; Ruiz Valderas 2000; } \\
\text { Martín Camino 1998: 13, lám. IV }\end{array}$ \\
\hline Estrecho & - Melilla & II a.C. & Villaverde 2004: fig. 17 \\
\hline N.de África & - Cartago & III a $1^{\text {a }}$ mitad del II a.C. & $\begin{array}{l}\text { Bechtold 2014: 99, fig. 5,c; 106, fig. 7, k; Lancel } \\
\text { 1987: 107-108, lám. 8, 212a }\end{array}$ \\
\hline
\end{tabular}




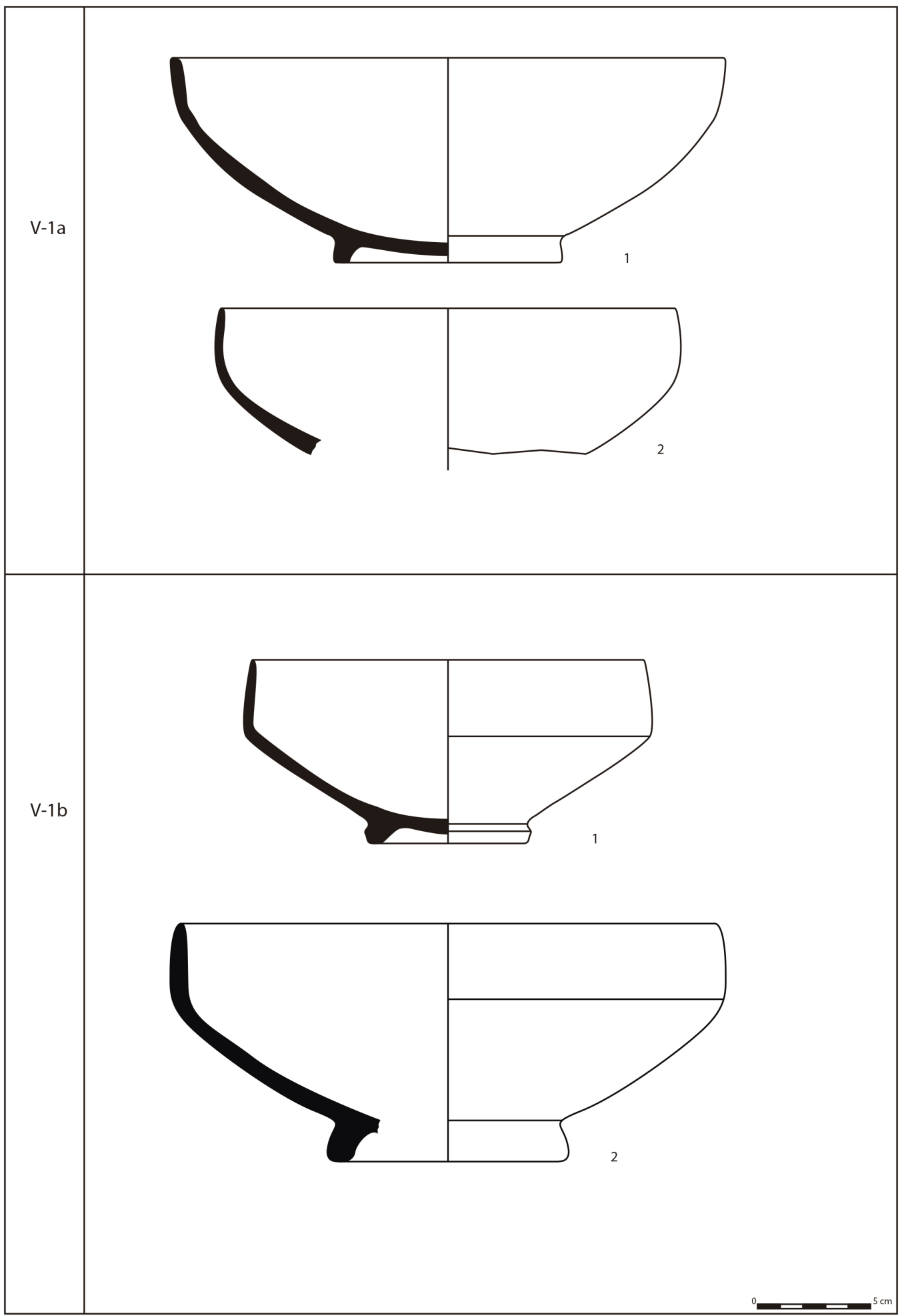

Figura 6. V-1a. 1: Ibiza, AR-33. 2: Olbia. V-1b. 1: Na Guardis (Mallorca). 2: Olbia. 
Tabla 22.

\begin{tabular}{|c|c|c|c|}
\hline Área & Yacimientos & Cronología & Bibliografía \\
\hline \multirow{8}{*}{ Cerdeña } & - Monte Sirai & III-II a.C. & Campanella 1999: fig. 21, nº 155-157 \\
\hline & - Sulkis & III-II a.C. & Campanella 2008: 163 \\
\hline & - Tharros & III-II a.C. & Amadori et al. 2004: fig. 1, 7 \\
\hline & - El Sinis & III-II a.C. & Del Vais 2014: 116, fig. 11, 1-9 \\
\hline & - Cagliari & $1^{\mathrm{a}}$ mitad del s. II a.C. & Tronchetti 2001: 286-287, lám. V \\
\hline & - Neápolis & & Museo de Oristano \\
\hline & - Olbia & III-II a.C. & Amadori et al. 2009: fig. 1, Olb 6 \\
\hline & - Pauli Stincus y Truncu e'Molas & & (inéditos) \\
\hline \multirow{2}{*}{ Ibiza } & - Ibiza & III-II a.C. & Ramon 2012: fig. 7, nº 57 \\
\hline & - Avinguda d'Espanya & Finales III a mitad II a.C. & Duarte 2016: 85-87, fig. 27 \\
\hline Estrecho & - Bahía de Cádiz & Finales IV a fines III a.C. & Niveau 2009: 248, fig. 12, forma VIII \\
\hline N. de África & - Cartago & III a.C. & Bechtold 2014: 99-100, fig. 5,d; 102, fig. 6, g, f \\
\hline
\end{tabular}

Recuerda a la forma Lamb. 28 de la Campaniense A, o a la especie F-2640 de Morel. Para Del Vais (2007: $175)$ corresponde a la última variante de este tipo de cuencos anchos poco profundos, y se fecharía en la primera mitad del siglo II a.C.

En Cerdeña, de nuevo dos formatos: uno más pequeño, de 13-14 cm de diámetro de borde, y otro mayor, de 17-18 cm. Las rdp están entre 2 y 3,5. Muy frecuente, como la V-2a. En Ibiza encontramos un formato más pequeño que en la variante anterior, de 11-14 cm y rdp de 3,6/4,5. (Tabla 23)

V-3: Cuenco ancho poco profundo con inflexión en la parte alta de la pared y borde engrosado al exterior de sección cuadrada o trapezoidal (fig. 8).

Podría acercarse a la especie F-2630 de Morel. Similar a una forma cartaginesa de la primera mitad del siglo II a.C. (Lancel 1987:107, lám. 9, 211a3) No la encontramos en Cerdeña.

En Ibiza, los diámetros de borde están entre 20 y 25 $\mathrm{cm}$, y la rdp va de 3,4 a 5. (Tabla 24)

V-4: Cuenco ancho poco profundo, de borde recto apuntado y muy abierto o exvasado, con inflexión o carena media. La parte superior de la pared, a menudo algo cóncava (fig. 8).

Aproximadamente especie F-2640 de Morel.
En Cerdeña la encontramos con diámetros de borde de 12/14 cm, y rdp de 3,5/4. En Ibiza, con el mismo tamaño y rdp de 2,5/3,7 (más profunda que en Cerdeña). (Tabla 25)

V-5: Cuenco ancho poco profundo de paredes verticales o algo exvasadas, que presenta dos surcos junto al borde por el exterior (fig. 8).

Similar a la Lamb 1, Morel F-2320/50. Tanto en Ibiza como en Cerdeña, los diámetros de borde oscilan entre 12 y $15 \mathrm{~cm}$, y la rdp entre 3,5 y 4,5. En ambas islas se presenta tanto en cocción reductora (pasta gris) como oxidante. Se fecha desde finales del siglo II a.C a la mitad del I d.C. Tronchetti la fijó y dató bien dentro de la producción sarda de pasta gris, aunque la hemos encontrado en Neápolis también en cocción oxidante. (Tabla 26)

\section{VI: Varios}

Comprende en principio píxides y tapaderas.

VI-1: Píxide (fig. 9).

Versión de las píxides tan abundantes en las series de cerámicas de barniz negro tardías etruscas y campanas. Aproximadamente Lamb. 3 y Morel F-7530/50.

En Ibiza conocemos una pieza, procedente del Puig des Molins. En Cerdeña, se presentan dentro de la cerámica "gris sarda" de cocción reductora. 


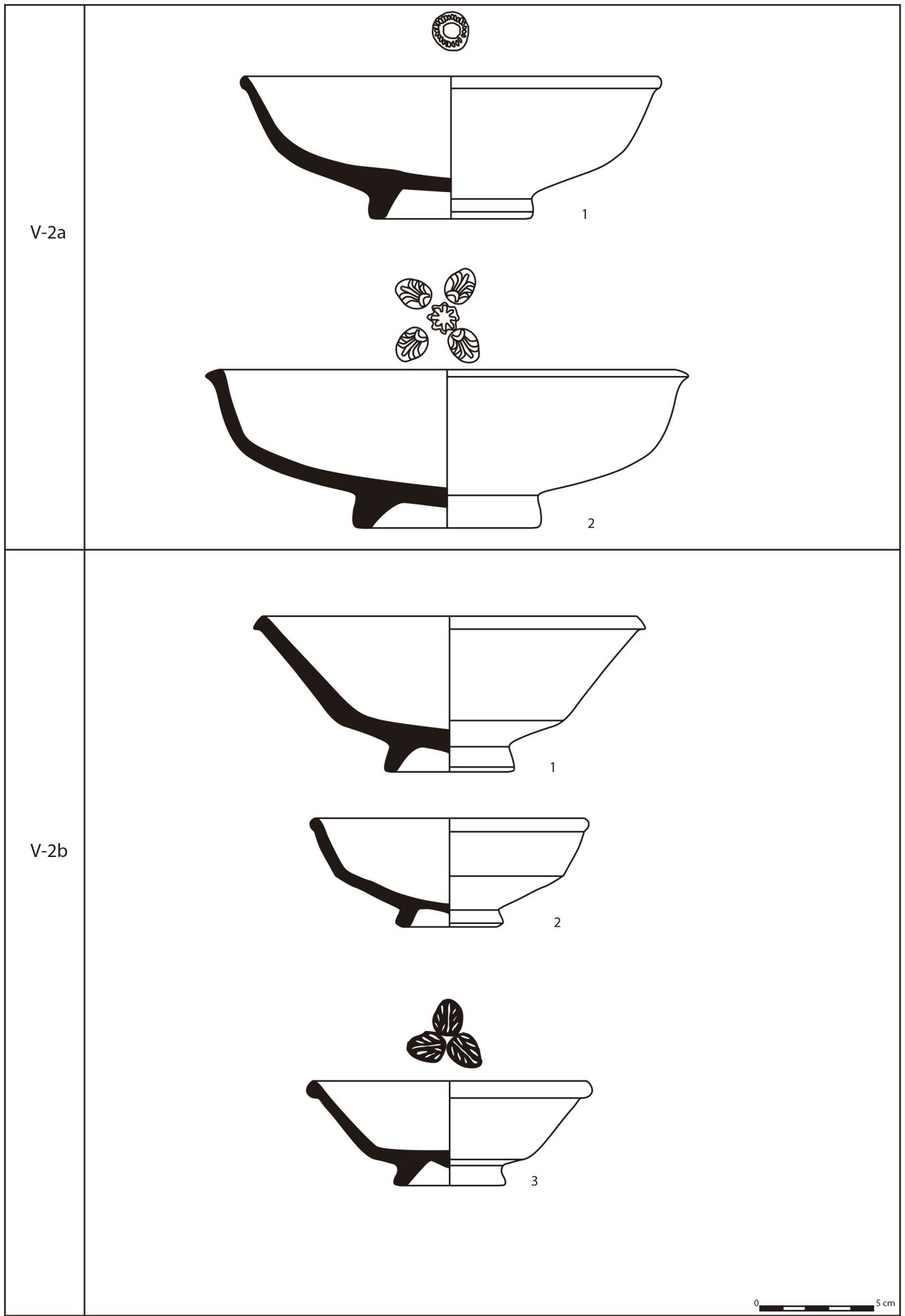

Figura 7. V-2a. 1: Cagliari, Cisterna della Cittadella. 2: Ibiza, AR-33. V-2b. 1: Ibiza, Puig des Molins. 2: Pauli Stincus. 3: Na Guardis (Mallorca). 
Tabla 23.

\begin{tabular}{|c|c|c|c|}
\hline Área & Yacimientos & Cronología & Bibliografía \\
\hline \multirow{7}{*}{ Cerdeña } & - Monte Sirai & III-II a.C. & Campanella 1999: fig. 6, nº 158-160 \\
\hline & - Tharros & III-II a.C. & Amadori et al. 2004: fig. 1, 4 a 6 \\
\hline & - El Sinis & $1^{\mathrm{a}} \operatorname{mitad}$ II a.C. & Del Vais 2014: 116, fig. 11, 1-9 \\
\hline & - Cagliari & Mitad III a mitad II a.C. & Tronchetti 2001: 283, lám. IV; 286, lám. V \\
\hline & - Neápolis & & Museo de Oristano \\
\hline & - Olbia & III-II a.C. & Amadori et al. 2009: fig. 1, Olb 4 \\
\hline & - Pauli Stincus y Truncu e'Molas & & (inéditos) \\
\hline \multirow{2}{*}{ Ibiza } & - Ibiza & $2^{\mathrm{a}} \operatorname{mitad}$ III a.C. & Ramon 2012: 596, fig. 7, 74-75 \\
\hline & - Avinguda d'Espanya & Finales III a mitad II a.C. & Duarte 2016: 85-87, fig. 27 \\
\hline Baleares & - Na Guardis & $\begin{array}{l}\text { Fines del III a } \\
\text { 130/120 a.C. }\end{array}$ & Guerrero 1999: 13-14, fig. 7, 4 \\
\hline $\begin{array}{l}\text { Fachada } \\
\text { mediterránea }\end{array}$ & - La Malladeta & & Rouillard et al. 2014: 109, fig. 118 \\
\hline \multirow[b]{2}{*}{ Estrecho } & - Bahía de Cádiz & Finales del III y II a.C. & Niveau 2009: 248, fig. 12, forma VIII \\
\hline & - Kuass & & $\begin{array}{l}\text { Kbiri Alaoui 2007: 181, figs. 149, } 152 \text { y } 153 \text {, } \\
\text { forma } 7\end{array}$ \\
\hline
\end{tabular}

Tabla 24

\begin{tabular}{|l|l|c|l|}
\hline \multicolumn{1}{|c|}{ Área } & \multicolumn{1}{|c|}{ Yacimientos } & \multicolumn{1}{c|}{ Cronología } & \multicolumn{1}{c|}{ Bibliografía } \\
\hline \multirow{3}{*}{ Ibiza } & - Ses Figueretes y Hort d'en Xim & Finales III a II a.C. & Ramon 2012: 596, fig. 7, 74-75 \\
\cline { 2 - 4 } & - Can Vicent & $2^{\text {a mitad II a.C }}$ & $\begin{array}{l}\text { Pérez Ballester y Gómez Bellard 2009: 56-57, } \\
\text { fig. 13). }\end{array}$ \\
\cline { 2 - 4 } & - Avinguda d'Espanya 3 & II a.C. & Duarte 2016: 87, fig. 28 \\
\hline Baleares & - Na Guardis & $\begin{array}{c}2^{a} \text { mitad del III a } \\
130 / 120 \text { a.C. }\end{array}$ & Guerrero 1999: 15-16, fig. 9, tipo 1.5b \\
\hline $\begin{array}{l}\text { Fachada } \\
\text { mediterránea }\end{array}$ & - La Malladeta & & Rouillard et al. 2014:109, fig. 118, $\mathrm{n}^{\circ} 9$ \\
\hline
\end{tabular}

Los formatos son variados: diámetros de borde entre 7 y $10 \mathrm{~cm}$ y rdp entre 1 y 2,5 en ambas islas. (Tabla 27)

\section{VI-2: Tapadera (fig. 9).}

Hemos clasificado aquí algunos fragmentos de borde rectilíneo y de fuerte inclinación, que podrían corresponder precisamente a tapaderas.

En Ibiza hay algunas piezas; una de ellas, de Can Vicent d'en Jaume tiene un diámetro de $10 \mathrm{~cm}$. (Tabla 28)

\section{CONCLUSIONES (tablas 29 y 30)}

¿Podríamos hablar de servicios en las mesas de los habitantes de Ibiza y Cerdeña? No, sin analizar también la presencia o ausencia en ellas de otras vajillas como las de barniz negro áticas o itálicas, o incluso aquellas sin cubierta específica, como ocurre por ejemplo en Cerdeña en Monte Sirai (Campanella 1999).

Sí podemos sin embargo trazar unas líneas generales sobre cuáles son los gustos que llevaron en cada 


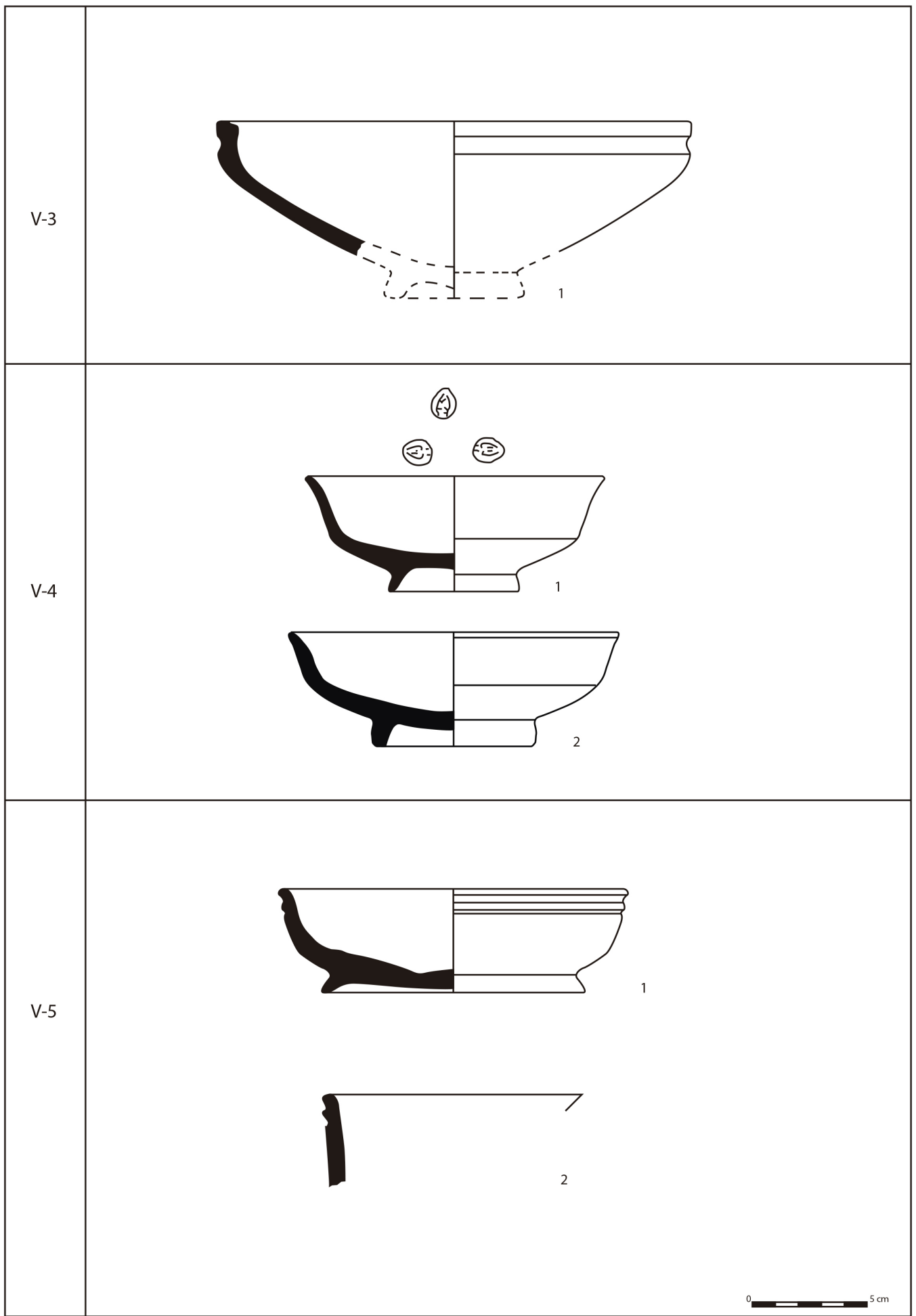

Figura 8. V-3. 1: Na Guardis (Mallorca).V-4. 1: Cagliari, Cisterna della Cittadella. V-5. 1: Ibiza, Ses países de cala d'Hort. 2: Neapolis. 
Tabla 25.

\begin{tabular}{|c|c|c|c|}
\hline Área & Yacimientos & Cronología & Bibliografía \\
\hline \multirow{2}{*}{ Cerdeña } & - Monte Sirai & III-II a.C. & Campanella 1999: fábricas 1 y 3 , fig. $24, n^{\circ} 200$ \\
\hline & - Cagliari & $1^{\mathrm{a}}$ mitad del II a.C. & Tronchetti 2001: 286, lám. VI \\
\hline \multirow{2}{*}{ Ibiza } & - Can Vicent & $2^{\mathrm{a}}$ mitad II a.C. & $\begin{array}{l}\text { Pérez Ballester y Gómez Bellard 2009: 55-56, } \\
\text { fig. } 9\end{array}$ \\
\hline & - Illa des Conills & $1^{\mathrm{a}} \operatorname{mitad}$ II a.C. & Pons 2005: fig. 14, 5 y 7 \\
\hline Baleares & - Mallorca & II y $1^{\mathrm{a}} \operatorname{mitad} \mathrm{I}$ a.C. & Guerrero 1999: 14, fig. 7, 2 y 3. \\
\hline \multirow[b]{2}{*}{ Estrecho } & - Bahía de Cádiz & II a.C. & Niveau 2009: 248, fig. 12, forma VIII \\
\hline & - Kuass & & $\begin{array}{l}\text { Kbiri Alaoui 2007: 181, figs. 149, } 152 \text { y 153, } \\
\text { forma } 7\end{array}$ \\
\hline
\end{tabular}

Tabla 26

\begin{tabular}{|c|l|c|l|}
\hline \multicolumn{1}{|c|}{ Área } & \multicolumn{1}{|c|}{ Yacimientos } & \multicolumn{1}{c|}{ Cronología } & \multicolumn{1}{c|}{ Bibliografía } \\
\hline \multirow{2}{*}{ Cerdeña } & - Sulkis & Finales II a mitad I a.C & Morel 1963: 25; Tronchetti 1996: 32-33, láms. 3,10 y 4,2 (grises) \\
\cline { 2 - 4 } & - Neápolis & & Museo de Oristano (oxidante) \\
\hline $\begin{array}{l}\text { Fachada } \\
\text { mediterránea }\end{array}$ & - Cartagena & Finales II a.C. & Anfiteatro, inéditas, ibicencas. \\
\hline
\end{tabular}

Tabla 27.

\begin{tabular}{|l|l|l|l|}
\hline \multicolumn{1}{|c|}{ Área } & \multicolumn{1}{|c|}{ Yacimientos } & \multicolumn{1}{c|}{ Cronología } & \multicolumn{1}{c|}{ Bibliografía } \\
\hline Ibiza & - Puig des Molins & Finales II a.C. a 1 1 mitad I a.C. & Ramon 2012: 506, nº82 \\
\hline Cerdeña & - Truncu e'Molas & & (Inéditos) \\
\hline
\end{tabular}

Tabla 28.

\begin{tabular}{|l|l|c|l|}
\hline \multicolumn{1}{|c|}{ Área } & \multicolumn{1}{|c|}{ Yacimientos } & Cronología & \multicolumn{1}{c|}{ Bibliografía } \\
\hline Cerdeña & - Neápolis & & Museo de Oristano \\
\hline Ibiza & - Can Vicent & $2^{\text {a mitad II a.C. }}$ & Pérez Ballester y Gómez Bellard 2009: 59, fig. 9 \\
\hline & - Avinguda d'Espanya & Sin datar & Duarte 2016: 89, fig. 32 \\
\hline
\end{tabular}

área geográfica a escoger determinada forma y no otra de manera preferente. El porqué dependerá de una serie de factores: presencia de vasos áticos e itálicos mayoritarios (imitando los mismos cuando estos faltan; complementando el repertorio de los que no son comercializados); continuidad de una tradición cerámica local arraigada; vinculación formal a un consumo de alimentos cocinados de determinada manera; situación social de los consumidores (considerando al menos ambientes urbanos / rurales), etc. Como se ve, una tarea digna de mayor espacio y dedicación, que ya se ha acometido en la bahía de Cádiz y el Bajo Valle del 


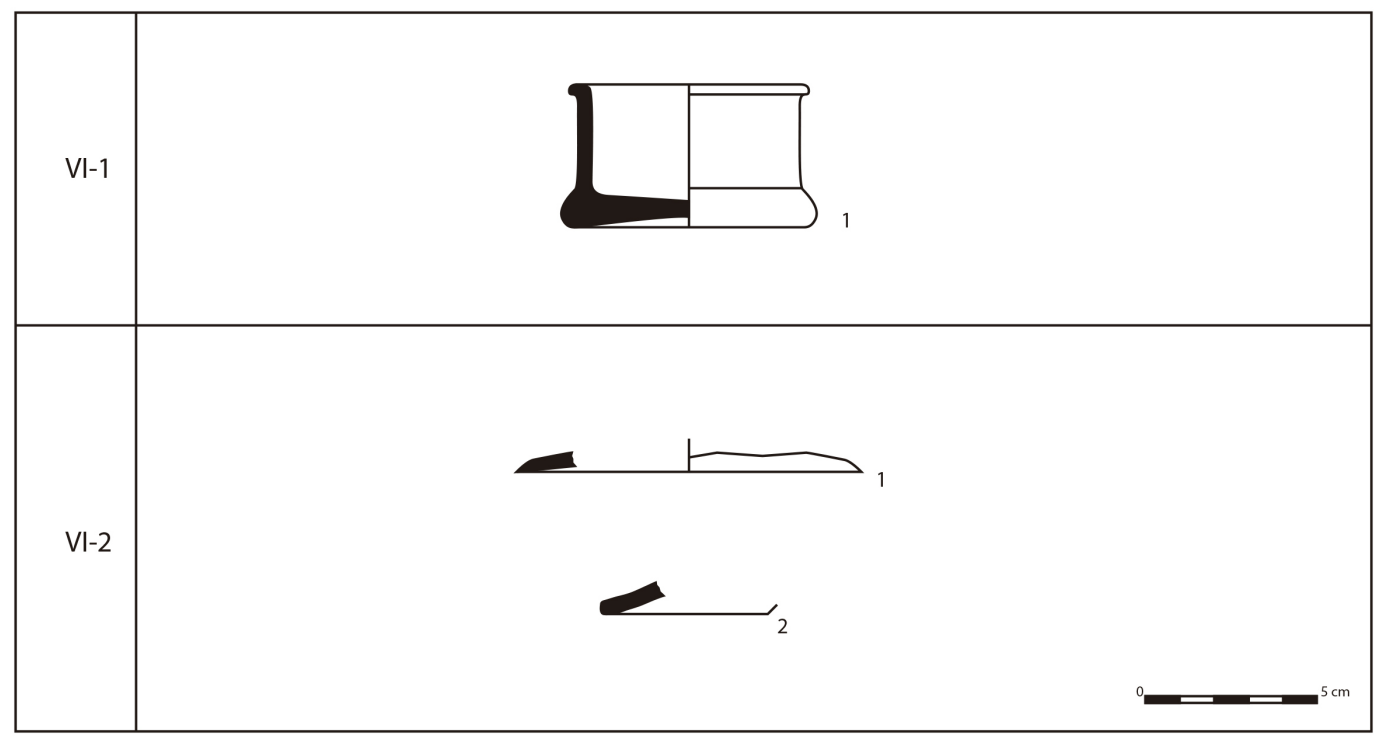

Figura 9. VI-1. 1: Ibiza, Puig des Molins?. VI-2. 1: Ibiza, Can Vicent d'en Jaume. 2: Pauli Stincus.

Guadalquivir (Niveau 2014; Sáez Romero 2014; Moreno Mejías 2016).

Estudiaremos el caso de Cerdeña e Ibiza, añadiendo lo que hemos podido observar en otras zonas productoras con desigual información: muy completa en la bahía de Cádiz, más escasa al otro lado del Estrecho (Kuass) y en Cartago.

\subsection{Cerdeña}

Las primeras formas documentadas, de origen ático, tienen su origen ya en el siglo IV. Durante el siglo III se usaron preferentemente vasos que recuerdan a las formas áticas y primeras itálicas: V-2a (Lamb. 22) que será paulatinamente sustituída por la V-2b (Lamb. 28); IV1a (Lamb. 27ab) y IV-1b (Lamb. 25 y 21/25). Son relativamente profundas, y sin una funcionalidad clara: a las primeras se les ha asignado un uso como vaso de beber, a las segundas como un vaso multifuncional y a las terceras para contener salsas, aditivos, o incluso para beber.

Llama la atención la escasa representación de formas llanas específicas para presentar o consumir alimentos secos o en caldos cortos, cocinados o no. Se documenta el "plato de pescado" I-2 (Lamb. 23), pero sin la frecuencia de otros yacimientos centromediterráneos que veremos.

También es interesante comprobar que los dos cuencos anchos poco profundos $\mathrm{V}-2 \mathrm{a}$ y $\mathrm{V}-2 \mathrm{~b}$ presentan formatos distintos: uno pequeño $(12 / 14 \mathrm{~cm})$ y otro mayor $(17 / 18 \mathrm{~cm})$. ¿Consumo individual y consumo colectivo o comunitario? ¿Uno para beber y otro para servir y consumir comidas líquidas o semisólidas? No estamos seguros. Además no tenemos datos suficientes para pensar tampoco en una sucesión temporal de los dos formatos en la isla.

El cuenco IV-1a presenta siempre un formato relativamente pequeño: $14 / 16 \mathrm{~cm}$ de diámetro de borde, recordando al de los mismos boles áticos o a los de Pequeñas Estampillas itálicos contemporáneos, reconocidos como de uso individual.

El siglo II a.C., tanto en Cerdeña como en Ibiza, significará un aumento del repertorio formal pero también una disminución paulatina de esta vajilla a favor de las de barniz negro itálico. Las formas llanas cobran protagonismo como elemento básico de la vajilla de mesa, a través de las páteras II-1a (aprox Lamb. 55) y II-1b, que son habituales durante los tres primeros cuartos del siglo II a.C. así como con los platos I-4 de borde ondulado y posible raíz ática, aunque luego aparecen versionados en la forma Lamb. 6 del barniz negro itálico. Sus formatos son uniformes: entre 18 y $24 \mathrm{~cm}$ de diámetro de borde y no muy profundos, útiles para el servicio individual. Otros más pequeños $(8 / 10 \mathrm{~cm})$ de la forma II-1a podrían ser usados para aditivos o condimentos.

Junto a ellos, continúan los cuencos IV-1a de uso individual, los cuencos poco profundos V-2b y V-4 (aprox. Lamb. 34), ambos en el formato pequeño (12/14 cm), lo 
que hace pensar en una tendencia a vasos de beber individuales más pequeños conforme avanza el tiempo.

A finales del siglo II a.C. la vajilla de mesa engobada será sustituida por la llamada "gris sarda", realizada en cocción reductora y con formas del repertorio de la cerámica de Cales Media y Tardía. En cocción oxidante encontramos reproducidas, aunque en escaso número, las páteras Lamb. 5 (II-3) y Lamb. 5/7 (II-5), el cuenco ancho y poco profundo Lamb. $1(\mathrm{~V}-5)$ y la píxide Lamb. 3 (VI-1).

\subsection{Ibiza}

Como hemos comentado para Cerdeña, también en Ibiza las formas de las primeras cerámicas engobadas tienen sus precedentes en otras del siglo IV a.C., en este caso de cocción reductora (Fernández y Granados 1980).

Las formas más frecuentes durante la primera mitad del III debieron ser los platos I-2 (Lamb. 23) y los boles o cuencos IV-1a (Lamb. 27ab), siendo muy escaso el cuenco ancho poco profundo V-2a (Lamb. 22) mayoritario en Cerdeña. Este sería el servicio básico plato/ cuenco de este momento, aunque no deberíamos olvidar la producción contemporánea en pastas grises, donde el mismo plato de pescado I-2, el cuenco IV-1a en sus versiones grande y pequeña y cuencos anchos poco profundos como la V-2 o V-4 son también frecuentes.

A partir de la mitad del siglo III continúan los platos I-2, se incorporan las páteras de borde engrosado II-1a (Lamb. 55) y los cuencos anchos poco profundos. Entre estos destacan los de borde recto V-1a y V-1b, que constituyen junto a la I-2 las formas más numerosas en Ibiza y su área de influencia y V-2b (Lamb. 28).

En cuanto a los formatos, los platos I-2 son similares en Ibiza y Cerdeña $(18 / 22 \mathrm{~cm})$. Las páteras II-1a presentan un formato mediano-grande, no apareciendo el formato pequeño que encontramos en Cerdeña.

Las producciones engobadas ibicencas continúan durante el siglo II, rarificándose en la primera mitad del I a.C. En cuanto a las formas llanas, el plato I-2 no supera la mitad del siglo; es sustituido por una nueva forma, I-1a (Lamb. 36), y continúan las páteras II1a, especialmente numerosas. Entre los cuencos, hace ahora su aparición la forma III-1 (aprox. Lamb. 31/33) que es sin duda un vaso para beber individualmente, con diámetros de borde entre 13 y $16 \mathrm{~cm}$.

El cuenco ancho poco profundo V-2b (Lamb. 28), solo se presenta en el formato pequeño $(11 / 14 \mathrm{~cm})$. Estaríamos también ante un vaso para beber de forma individual. Por el contrario, las formas más frecuentes, V-1a y V-1b, presentarán formatos medio-grandes (18$26 \mathrm{~cm}$ ), hasta finales del siglo II a.C. Las consideramos multifuncionales y su uso podría ser el de presentación y consumo de alimentos cocinados con caldo, o para beber en común.

Los boles y cuencos IV-1a presentan dos formatos: uno mayor y más profundo entre 18 y $20 \mathrm{~cm}$, más similar a la Lamb. 26 o Lamb. 27B, y el otro, más frecuente, de 13/14 cm (Lamb. 27b). Quizás estemos ante un recipiente para presentar y consumir alimentos líquidos y semisólidos (el mayor) y otro para beber de manera individual (el menor). El bol IV-1a no pasará del último cuarto del siglo II, mientras que el cuenco profundo III-1 (Lamb. 31/33) llegará a la primera mitad del I a.C. De esta fase tardía son, como en Cerdeña, nuevas formas que reproducen parte del repertorio de la cerámica de barniz negro de Cales Media y Tardía

A finales del siglo II aparecerán, como en Cerdeña, nuevas formas escasamente representadas y relacionadas con los repertorios de la Campaniense B, en concreto con el de las cerámicas de barniz negro de Cales Media y Tardía: páteras II-3 (similar a la Lamb. 5), la más reciente II-5 (aprox. Lamb. 5/7), el cuenco ancho poco profundo V-5, que reproduce la Lamb. 1 o una variante de ella y la píxide VI-1 (Lamb. 3). Como en Cerdeña, hasta los últimos momentos de la producción coexistirán con otros vasos de cocción reductora de las mismas formas.

\subsection{Cádiz}

En la bahía de Cádiz (Sáez Romero 2014: 40-60) desde finales del siglo $\mathrm{V}$ y hasta la mitad del siglo III a.C. las formas predominantes serán el "plato de pescado" forma I-2 y el pequeño cuenco de borde reentrante IV$1 \mathrm{~b}$, a las que se añadirá, desde inicios del siglo III, el cuenco poco profundo V-2a (Lamb. 22) junto a otras formas que no identificamos en nuestra área de estudio.

A partir de la mitad del III seguirán las formas anteriores, a las que se sumará el cuenco de borde reentrante IV-1a (Lamb. 27a/b), el cuenco poco profundo V-2b (aprox. Lamb. 28, evolución del V-2a), y los primeros ejemplares del plato de borde vuelto I-1a (aprox. Lamb. 36).

En el siglo II aumenta el número de formas llanas y poco profundas: continúan débilmente los platos I-2 y aumentan los I-1a; se imitan otras formas de la Campaniense A y de la Cales Media y Tardía, páteras II1a y II-3 (Lamb. 55 y Lamb. 5) y platos I-4 (aprox. 
Tabla 29. Tabla cronológica de las formas, por cuartos de siglo.

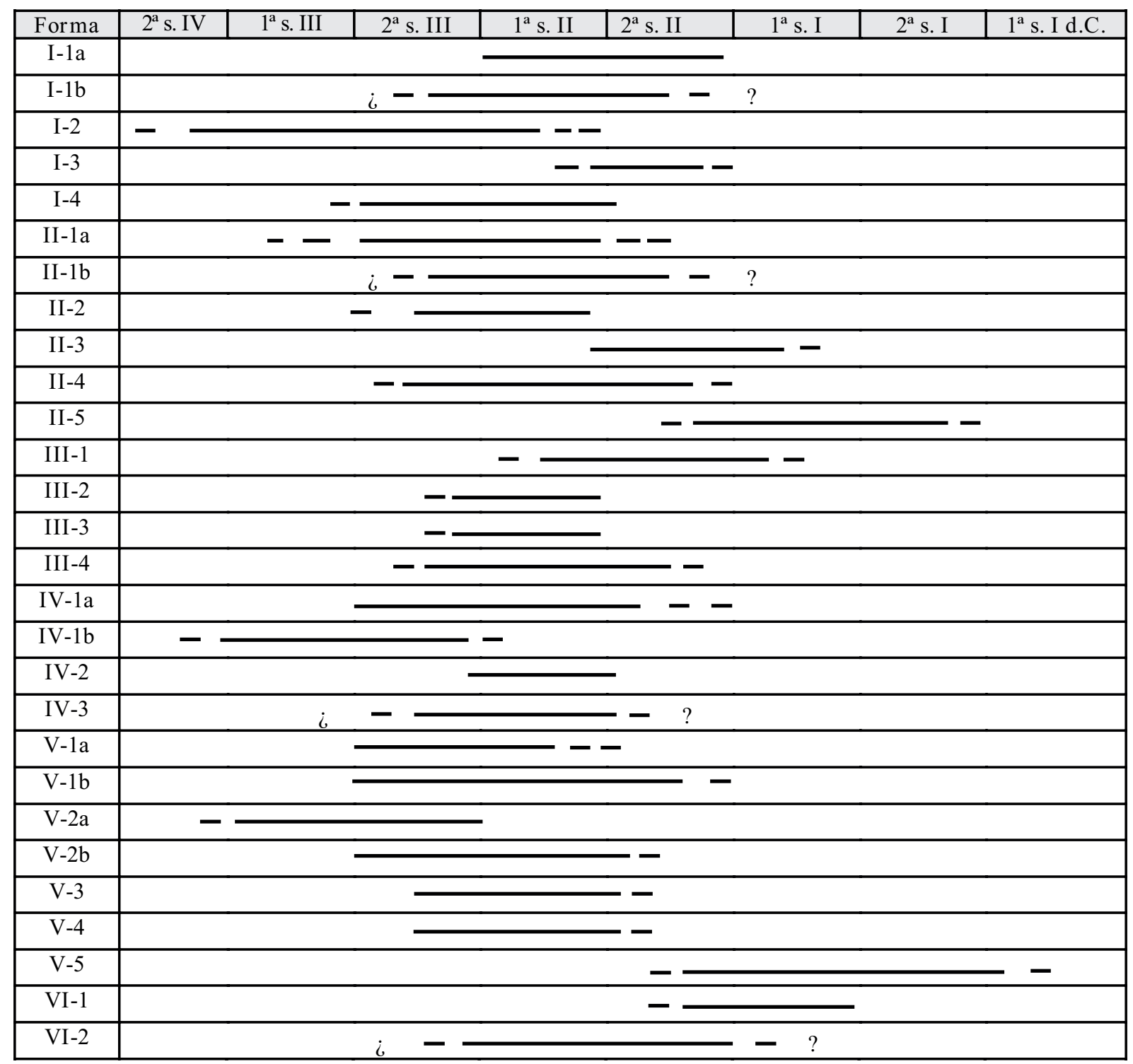

Lamb. 6), siguiendo un modelo relacionado seguramente con una continuidad en el modelo de consumo (van sustituyendo a los "platos de pescado"). En escaso número encontramos el pequeño cuenco IV-2 (aprox. Lamb. 34) y los cuencos profundos para beber III-1 (aprox. Lamb. 31/33). Seguirá también hasta el cambio de siglo II al I a.C. el bol de borde reentrante IV-1a (aprox. Lamb. 27a/b).

En cuanto a los formatos, el del plato I-2 es similar a los que hemos visto de Ibiza y Cerdeña: $18 / 22 \mathrm{~cm}$ de diámetro de borde, con profundidades diversas. Los cuencos o boles IV-1a mantienen también diámetros comunes: $13,5 / 14,5 \mathrm{~cm}$; los cuencos anchos poco profundos V-2a y V-2b se presentan solo en formato pequeño o muy pequeño, $8 / 11 \mathrm{~cm}$, como en Ibiza. Niveau de Villedary (2014: 153-155) ha propuesto que el plato I-2 (Kuass II) y luego I-1a (Lamb.36) y los cuencos IV-1b (Kuass IX) constituyen un servicio individual, donde el pequeño cuenco contendría salsas, especias, etc. para acompañar al pescado del plato I-2. Nosotros añadiríamos los cuencos de borde reentrante IV-1a, multifuncionales y los cuencos anchos poco profundos V-2a (Kuass VIII, Lamb. 22) y luego V-2b (Lamb. 28) de formato pequeño, para beber. 
Faltarían recipientes para contener alimentos líquidos o semisólidos, salvo que se presenten en otra clase cerámica o se consumiesen en cuencos como los IV-1a $\mathrm{y}$ los V-2a y b de formato grande.

Este servicio no se cumplirá sin embargo para los contextos rituales, donde la forma IV-1b es sustituida por boles de borde reentrante (IV-1a) y son frecuentes los cuencos para beber V-2a y V-2b y un "bolsal" sin asas (Kuass VII), como nuestra V-4.

Tampoco es igual en entornos indígenas del Bajo Guadalquivir, donde en contextos turdetanos los platos de pescado I-2 son igualados por distintos tipos de cuencos y a menudo no llegan siquiera al $20 \%$ del total. En algunos casos, como en El Gandul, se atestiguan talleres que producen a su vez imitaciones de las cerámicas engobadas gaditanas, con formas que llegarán al siglo I a.C. (Moreno Mejías 2016: 118-138).

\subsection{Kuass}

El panorama que observamos en Kuass es en casi todos los aspectos similar al que hemos visto en Cádiz, aunque cuenta con un repertorio menor y en general de peor calidad. Son mayoritarios los "platos de pescado" I-2, junto a los pequeños cuencos o copitas IV-1b, seguidos de los boles IV-1a. Podríamos estar ante un "servicio individual" semejante al observado en la bahía de Cádiz. Los cuencos anchos poco profundos se agrupan en Kuass todos ellos bajo la definición de "bolsal", englobando a nuestros V-1a, V-2b y V-4 y se relacionan con la forma Lamb. 22 (Kbiri Alaoui 2007: 180-181, figs. 150 y 153). Niveau de Villedary cree que las piezas de mejor calidad podrían ser gaditanas y el resto, de alfares locales. Confirma la existencia de un servicio mínimo individual doméstico (formas I-2 y IV-1b) y otro más complejo y variado en las necrópolis, como ocurre también en Cádiz (Niveau 2014: 123-156).

Es de señalar una importante novedad en el formato de las piezas. Los platos I-2 no superan los $16 \mathrm{~cm}$, estando todos entre 13 y $15 \mathrm{~cm}$ de diámetro de borde. Lo mismo ocurre con los cuencos anchos y poco profundos (V-1a, V-2b y V-4), que salvo excepciones concentran también sus diámetros de borde entre 13 y $15 \mathrm{~cm}$. Los boles IV-1a y las copitas IV-1b mantienen sus formatos pequeños $(14 / 16 \mathrm{~cm})$ o muy pequeños $(7 / 8 \mathrm{~cm})$ como en otras áreas geográficas.

Estamos pues ante una producción que prioriza la fabricación de vasos de uso individual, ya sea para comer (platos I-2 y quizás boles IV-1a) o para beber (cuencos anchos poco profundos V-1a, V-2b y V-4), junto a los pequeños vasitos auxiliares (IV-1b).

En Lixus (Bonet et al. 2005), apenas a una treintena de kilómetros de Kuass, en la fase antigua (siglo III-inicios del II a.C.) encontramos un "servicio" en el que el plato sigue siendo el de "pescado" I-2, y el cuenco el bol IV-1a, mejor que el pequeño IV-1b, que también se documenta.

En las llamadas series tardías, se documentan aquellas formas inspiradas en el repertorio de las cerámicas de barniz negro de Cales Media y Tardía: páteras Lamb. 5 (II-3), cuencos anchos poco profundos Lamb. 1 (V-5) y píxide Lamb. 3 (VI-1) (Bonet et al. 2005: 137-138).

\subsection{Cartago}

En el siglo III, especialmente hacia su segunda mitad, parecen predominar los "platos de pescado" I-2, los boles IV-1a, las copitas IV-1b y los cuencos anchos poco profundos V-2a (Lamb. 22). Menos frecuente es la forma $\mathrm{V}-1 \mathrm{~b}$, aunque es posible que sea el prototipo de la que más tarde veremos en Ibiza y en menor medida en Cerdeña. Lo mismo podemos decir del plato de borde ondulado I-4, que encontramos en Cerdeña y no en Ibiza.

Funcionalmente, en Cartago y en el siglo III tendríamos platos de presentación y consumo de alimentos secos o en caldos cortos (¿pescados?): I-2 y I-4; cuencos multifuncionales que podrían contener alimentos líquidos o semisólidos o servir para beber: IV-1a, V-2a; y copitas para aditivos, salsas o también para beber.

Durante la primera mitad del II continúan presentes los platos I-2 y I-4, a los que se añade el I-1a (aprox. Lamb. 36) en un formato pequeño, como en Cerdeña; siguen también los boles IV-1a, con sus dimensiones habituales, mientras que las copitas IV-1b son sustituidas por las IV-2 (aprox. Lamb. 34); y los cuencos anchos poco profundos (grupo V) prácticamente desaparecen.

En resumen, en la primera mitad del siglo II continúan los platos para consumo I-2, I-4 y I-1a; les acompañan el cuenco multifuncional IV-1a y la copita IV-2; un repertorio escaso e incompleto, que indudablemente se debe a la irrupción de las producciones de barniz negro campanienses en Cartago en esta época, que acabará con la destrucción de la ciudad en el 146 a.C.

Hemos intentado presentar una sistematización, funcional y cronológica, de las producciones de vajilla de mesa engobadas púnico-helenísticas de Cerdeña e Ibiza. $\mathrm{Al}$ abordar también la problemática en otras áreas del Mediterráneo Central y Occidental, hemos observado 
Tabla 30. Frecuencia estimada de las formas por yacimientos o áreas geográficas.

\begin{tabular}{|c|c|c|c|c|c|}
\hline Forma & Cerdeña & Ibiza / Mallorca & Cádiz & Kuass & Carthago \\
\hline I-1a & $\mathrm{x}$ & $\mathrm{xx} / \mathrm{x}$ & $\mathrm{x} / \mathrm{xx}$ & & $\mathrm{x}$ \\
\hline $\mathrm{I}-1 \mathrm{~b}$ & $\mathrm{x}$ & & & & \\
\hline $\mathrm{I}-2$ & $\mathrm{x}$ & $\mathrm{xx}$ & $\mathrm{xxx}$ & $\mathrm{xxx}$ & $\mathrm{xx}$ \\
\hline $\mathrm{I}-3$ & & $\mathrm{x}$ & & & \\
\hline I-4 & $\mathrm{xx} / \mathrm{x}$ & & $\mathrm{x}$ & & $\mathrm{x}$ \\
\hline II-1a & $\mathrm{xx}$ & $\mathrm{xx}$ & $\mathrm{x}$ & & $\mathrm{x}$ \\
\hline II-1b & $\mathrm{x}$ & & & & \\
\hline II-2 & $\mathrm{x}$ & $\mathrm{x}$ & & & \\
\hline II-3 & & $\mathrm{x}$ & $\mathrm{x}$ & & \\
\hline II-4 & $\mathrm{x}$ & $\mathrm{x}$ & & & \\
\hline II-5 & $\mathrm{x}$ & $\mathrm{x}$ & & & \\
\hline III-1 & $\mathrm{x}$ ? & $\mathrm{xx}$ & $\mathrm{x}$ & & $\mathrm{x}$ ? \\
\hline III-2 & & $\mathrm{x}$ & & & \\
\hline III-3 & $\mathrm{x}$ & & & & \\
\hline III-4 & & $\mathrm{xx}$ & & & \\
\hline IV-1a & $\mathrm{xxx}$ & $\mathrm{xxx}$ & $\mathrm{xx}$ & $\mathrm{xx}$ & $\mathrm{xx}$ \\
\hline IV-1b & $\mathrm{xx}$ & $\mathrm{x}$ & $\mathrm{xxx}$ & $\mathrm{xxx}$ & $\mathrm{xx}$ \\
\hline IV-2 & $\mathrm{x}$ & $\mathrm{x}$ & $\mathrm{x}$ & & $\mathrm{x}$ \\
\hline IV-3 & $\mathrm{x}$ & & & & \\
\hline V-1a & $\mathrm{x}$ & $\mathrm{xx}$ & & $\mathrm{xx}$ & \\
\hline$V-1 b$ & $\mathrm{x}$ & $\mathrm{xx} / \mathrm{xxx}$ & & & $\mathrm{x}$ \\
\hline $\mathrm{V}-2 \mathrm{a}$ & $\mathrm{xx} / \mathrm{xxx}$ & $\mathrm{x}$ & $\mathrm{xx}$ & & $\mathrm{xxx}$ \\
\hline$V-2 b$ & $\mathrm{xxx}$ & $\mathrm{xx}$ & $\mathrm{xx}$ & $\mathrm{x}$ & \\
\hline $\mathrm{V}-3$ & & $\mathrm{x}$ & & & $\mathrm{x}$ \\
\hline$V-4$ & $\mathrm{xx}$ & $\mathrm{x}$ & $\mathrm{x}$ & $\mathrm{x}$ & \\
\hline $\mathrm{V}-5$ & $\mathrm{x}$ & $\mathrm{x}$ & & & \\
\hline VI-1 & $\mathrm{x}$ & $\mathrm{x}$ & & & \\
\hline VI-2 & $\mathrm{x}$ & $\mathrm{x}$ & & & \\
\hline
\end{tabular}

que aunque la información disponible es muy desigual, hay coincidencias notables entre las formas más frecuentes en las distintas zonas. Siguen siendo útiles y necesarias las tipologías regionales como las de la bahía de Cádiz o las de Kuass, correspondientes a producciones bien identificadas con talleres de producción propios.
Falta por hacer, a nivel regional, la contextualización de las distintas producciones engobadas con el resto de la vajilla cerámica que las acompaña: común, de barniz negro, de barniz rojo, etc., que nos permitiría matizar la importancia que tuvo esta clase cerámica en las mesas de nuestros antepasados, así como su funcionalidad, 
completada con el contexto de recipientes de cocina contemporáneos y los ocasionales análisis de restos biológicos hallados en ellos.

Esperamos que este trabajo sea un primer paso en esa dirección.

\section{Agradecimientos}

Este trabajo se ha realizado en el marco del proyecto HAR2016-76100: "Surachi y la implantación fenicia en el Sinus Oriental (Cerdeña)". Ministerio de Economía y Competitividad, IP: Carlos Gómez Bellard.

Nuestro agradecimiento al equipo de excavación de Pauli Stincus, dirigido por el prof. Peter Van Dommelen, que nos permitió el estudio de sus materiales. Igualmente al profesor R. Zucca, a E. Garau y a todo el personal del Museo de Oristano, por las facilidades dadas para la consulta de los materiales de Neápolis.

Victor Guerrero in memoriam.

\section{BIBLIOGRAFÍA}

Adroher Auroux, A.M. y Caballero Cobos, A. (2012): "Imitaciones de Campaniense en el mediodía peninsular. La cerámica gris bruñida republicana, en Bernal, D. y Ribera, A. (eds.) Cerámicas Hispanorromanas II. Problemas regionales: 23-38, Cádiz, Universidad de Cádiz.

Amadori, M.L.; Del Vais, C.; Fabbri, B. y Lanza, S. (2004): "La cerámica punica a vernice nera da Tharros (Cabras-Oristano): le letture storiche e indagine archeometriche", en Berti, F.; Fabbri, B.; Gualtieri, S. y Guarnieri Ch. (eds.) Metodologia di Ricerca e Obiettivi degli Studi; lo Stato dell'Arte: 39-58, Bologna, University Press.

Amadori, M.L.; Del Vais, C.; Ercolani, G. y Raffaeli, G. (2006): "Studio archeometrico sulle ceramiche puniche a vernice nera", en Acquaro, E. y Cerassetti, B. (eds.) Pantelleria Punica, Studi e Scavi, 15: 208-237, Bologna, Università di Bologna.

Amadori, M.L.; Del Vais C. y Raffaeli, G. (2009): “Indagine archeometriche sulla cerámica púnica a vernice nera dall'ex Mercato di Olbia" en Le classi ceramiche. Situazioni degli studi: 111-120, (Atti Roma 2006), Bari, Edipuglia.

Aranegui Gascó, C. (ed.) (2001): Lixus. Colonia fenicia y ciudad púnico-mauritana. Apuntes sobre la ocupación medieval, Saguntum Extra 4, Valencia, Universidad de Valencia.
Aranegui Gascó, C. (ed.) (2005): Lixus-2. Ladera Sur. Excavaciones arqueológicas marroco-españolas en la colonia fenicia. Campañas 2000-2003, Saguntum Extra 6, Valencia, Universidad de Valencia.

Aranegui Gascó, C. y Hassini, H. (eds.) (2010) : Lixus-3. Área suroeste del sector monumental (Cámaras Montalbán) 2005-2009, Saguntum Extra 8, Valencia, Universidad de Valencia.

Bats, M. (1988) : Vaiselle et alimentation à Olbia de Provence (v.350 - v.50 av. J-C.) Modèles culturels et catégories céramiques. Suppl. 18 à Revue Archéologique de la Narbonnaise, Paris, Editions du CNRS.

Bats, M. (1993): "Céramique à pâte claire massaliète et de tradition massaliète", en Py, M. (ed.) Dictionnaire des Céramiques Antiques en Méditerranée nord-occidentale : 206-221, Lattara 6, Lattes, Edition de l'Association pour la recherche archéologique en Languedoc oriental.

Bechtold, B. (2007) : “Alcune osservazioni sui rapporti commerciali fra Cartagine, la Sicilia occidentale e la Campania (IV - metà del II sec. a.C.) : nuovi dati basati sulla distribuzioni di ceramiche campane e nordafricane/cartaginesi", Bulletin Van de Vereeniging tot Bevordering der Kennis van de Antieke Beschaving 82 : 51-76.

Bechtold, B. (2014): "Imitazioni di produzioni greche/ italiche in contexto fenicio/punico. Le imitazioni locali di forme ceramiche allogene a cartagine (VII sec. a.C., en Graells, R.; Krueguer, M. ; Seuma, G y Sciortino, G. (eds.) El problema de "las imitaciones" durante la protohistoria en el mediterráneo centro-occidental. Entre el concepto y el ejemplo: 83-120, Iberia Archaeologica 18, Berlin, Deutsches Archäologisches Institut Madrid.

Belén, M. y Fernández Miranda, M. (1979): El fondeadero de Cales Coves (Alayor, Mallorca), Excavaciones Arqueológicas en España 101, Madrid, Ministerio de Cultura.

Bonet, H. y Mata, C. (1988): "Imitaciones de cerámicas campanienses en la Edetania y Contestania", Archivo Español de Arqueología, 61: 5-38.

Bonet, H. y Mata, C. (2002): El Puntal dels Llops. Un fortín edetano, Serie de Trabajos Varios del SIP 99, Diputación de València, València.

Bonet, H., Fumadó, I., Aranegui, C., Vives-Ferrándiz, J., Hassini, H., Kbiri Alaoui (2005): Las cerámicas de Kuass en Lixus, en Aranegui, C. (ed.), Lixus-2. Ladera Sur : 134-138, Saguntum Extra 6, Valencia, Universidad de Valencia.

Bridoux, V. (2006): “Les liens entre l'Oranie et les Baléares d'après un réexamen récent du matériel de 
la nécropole des Andalouses (III-I siècles avant J.-C.)", en L'Africa Romana : (Atti XVI Convegno, Rabat 2004) : 1649-1668, Roma, Carocci Editore.

Bridoux, V. (2008) : “Importations méditerranéennes du II s. av. n.è. en Maurétanie occidentale et hypothèses sur les voies d'acheminement", en Pérez Ballester, J. y Pascual, G. (eds), Comercio, redistribución y fondeaderos. La navegación a vela en el Mediterráneo: 419-434, Valencia, Universidad de Valencia.

Campanella, L. (1999): Ceramica púnica di età ellenistica da Monte Sirai, Roma, CNR.

Campanella, L. (2008): Il cibo nel mondo fenicio e púnico d'Occidente, Pisa-Roma, Fabrizio Serra Editore.

Camps, J. y Vallespir, A. (1998): Excavacions a Santa Ponça, Mallorca. El Turó de les Abeilles, "Col-lecció La Deixa" 1, Monografies de Patrimoni Històric, Palma de Mallorca.

Cuomo di Caprio, N. (2007): La Ceramica in Archeologia. 2. Antiche tecniche di lavorazione e moderni metodi di indagine. Nuova edizione ampliata, Studia Archeologica 144, Roma, L'Erma di Bretschneider.

Del Amo, M. (1970): "La cerámica campaniense de importación y las imitaciones campanienses de Ibiza”, Trabajos de Prehistoria 27: 201-258.

Del Vais, C. (2007): "Nuove ricerche sulla cerámica púnica a vernice nera”, en Angiolillo, S.; Giuman, M. y Pasolini, A. (eds.) Ricerca e confronti 2006. Giornate di studio di archeologia e storia dell'arte: 171 182, Cagliari, Università degli Studi di Cagliari.

Del Vais, C. (2014): "Il Sinis di Cabras in età púnica", en Minoja, M. y Usai, A. (eds.) Le sculture di Mont'e Prama. Contesto, scavi e materiali: 103136, Roma, Gangemi Editore.

Díes Cusí, E.; Van Dommelen, P. y Gómez Bellard, C. (2010): "Excavaciones en la granja púnica de Pauli Stincus (Terralba, Cerdeña)", Saguntum 42: 123-128.

Duarte, F.X. (2016): L'Avinguda d'Espanya 3 (Eivissa). Un taller púnic de producció cerámica. Saguntum Extra 18, Valencia, Universidad de Valencia.

Fernández Gómez, J.H. (1992): Excavaciones en la necrópolis del Puig des Molins (Eivissa), (campañas 1921-1929), Trabajos del Museo Arqueológico de Ibiza, 28-29, 3 vols., Ibiza, Museo Arqueológico de Ibiza y Formentera.

Fernández, J.H. y Granados, O. (1980): Cerámicas de imitación áticas del Museo Arqueológico de Ibiza, Trabajos del Museo Arqueológico de Ibiza, 2, Ibiza, Museo Arqueológico de Ibiza y Formentera.

Fernández Miranda, M. y Belén, M. (1977): Arqueología Subacuática en Menorca, Madrid, Fundación Juan March.
Garau, E. (2006): Da Qrthdsht a Neapolis. Trasformazioni del paesaggio urbano e periurbano, Ortacesus, Nuove Grafiche Puddu.

Gómez Bellard, C. (1995): "Un vertedero púnico rural en Ibiza: S'Olivar d'es Mallorquí", Saguntum 28: 151-166.

Guerrero Ayuso, V. (1980): "Las cerámicas pseudocampanienses ebusitanas en Mallorca", Archéologie en Languedoc 3: 169-194.

Guerrero Ayuso, V. (1984): El asentamiento púnico de $\mathrm{Na}$ Guardis. Excavaciones Arqueológicas en España, 133, Madrid, Ministerio de Cultura.

Guerrero Ayuso, V. (1997): La colonización púnica en Mallorca. La documentación arqueológica y el contexto histórico. Palma de Mallorca, El Tall.

Guerrero Ayuso, V. (1998): "Las importaciones cerámicas en la protohistoria de Mallorca", en Ramon, J.; Sanmartí, J.; Asensio, D. y Principal, J. (eds.) Les facies cerámiques d'importació a la costa ibèrica, les Balears i les Pitiuses durant el segle III a.C. i la primera meitat del segle II a.C.: 175-191, Arqueomediterrània, 4, Barcelona, Universitat de Barcelona.

Guerrero Ayuso, V. (1999): La cerámica protohistórica a torno en Mallorca (s. VI - I a.C.), BAR International Series, 770, Oxford, Archeopress.

Kbiri Alaloui, M. (2007): Revisando Kuass (Asilah, Marruecos), Saguntum Extra 7, València.

Lancel, S. (1987): "La céramique punique d'époque hellénistique ". Céramiques hellenistiques et romaines II : 99-137, Centre Recherches Histoire Ancienne, 36, Besançon, Université de Besançon.

Martín Camino, M. (1998): "Un contexto cerámico de finales del s. III a.C.: el vertedero púnico de la Plaza de San Ginés (Cartagena)", en Ramon, J.; Sanmartí, J.; Asensio, D. y Principal, J. (eds.) Les facies cerámiques d'importació a la costa ibèrica, les Balears $i$ les Pitiuses durant el segle III a.C. i la primera meitat del segle II a.C.: 9-28, Arqueomediterrània, 4, Barcelona, Universitat de Barcelona.

Mata, C., Bonet, H. (1992): "La cerámica ibérica: ensayo de tipología”. Homenaje a E. Pla: 117-173, Serie de Trabajos Varios del Servei d'Investigació Prehistòrica 89, Valencia, Diputación de Valencia.

Morel, J.P. (1980): "La céramique campanienne: Acquis et problèmes ". Céramiques Hellenistiques et Romaines, II : 85-122, Centre Recherches Histoire Ancienne, 36, Besançon, Université de Besançon.

Morel, J.P. (1981): La Céramique Campanienne. Les Formes, Bibliothèque Ècole Française d'Athènes et Rome, n 240, 2 vols., Rome, École Française d'Athènes et Rome. 
Morel, J.P. (1986): "La céramique à vernis noir de Carthage, sa diffusion, son influence", Carthage VIII, Cahiers d'Études Anciennes XVIII : 25-68.

Morel, J.P. (1990) : “Aperçu sur la chronologie des céramiques à vernis noir aux II et I siècles avant J.C.", en Gaule Interne et Gaule Meditérranéenne au II et I siècles av. J.C. Confrontations chronologiques: 55-71, Suppl. 21 à Rev. Arch. Narbonnaise, Narbonne, CNRS.

Morel, J.P. (1992): "Les échanges entre la Grande Grèce et la Gaule du VII siècle avant J.-Cr.". La Magna Graecia e il lontano Occidente : 247-294, Atti 29 convegno sulla Magna Graecia (Taranto, 1989), Roma, Istituto di Storia e Archeologia della Magna Grecia.

Moreno Mejías. V. (2016): La influencia púnica en las mesas turdetanas. La cerámica de tipo Kuass en el Bajo Valle del Guadalquivir. Sevilla, Diputación de Sevilla.

Niveau de Villedary, A.M. (2003): Cerámicas gaditanas tipo Kouass, Bibliotheca Archaeologica Hispana 21, Madrid, Real Academia de la Historia y Universidad de Cádiz.

Niveau de Villedary, A.M. (2009): "La cerámica tipo "Kouass", en Bernal, D. y Ribera, A. (eds.), Cerámicas Hispanorromanas. Un estado de la cuestión, I: 245-262, Cádiz, Universidad de Cádiz.

Niveau de Villedary, A.M. (2014): "El éxito de la vajilla helenística "tipo Kuass" ¿Resultado de la adopción de una moda estética o reflejo de transformaciones culinarias y comensales?”, en García Fernández, F.J. y García Vargas, E. (eds.), Comer a la moda: imitación de vajilla de mesa en Turdetania y la Bética occidental durante la Antigüedad (s. VI a.C. - VI d.C.): 119-174, Colección Instrumenta 46, Barcelona, Universidad de Barcelona.

Niveau de Villedary, A.M. y Campanella, L. (2006): "Finalmente a la mesa. El consumo de pescado en el mundo fenicio-púnico". Actas I Conferencia Internacional sobre la Historia de la Pesca en el ámbito del Estrecho, vol. II: 633-702, Sevilla, Instituto de Investigación y Formación Agraria y Pesca, Junta de Andalucía.

Pérez Ballester, J. (1995): "La actividad comercial y el registro arqueológico en la Carthago Nova republicana. Los hallazgos del área del Anfiteatro", Verdolay 7: 339-349.

Pérez Ballester, J. (1998): "El "Portus" de Carthago Nova. Sociedad y comercio tardo-helenísticos”. En Pérez Ballester J. y Pascual, G. (eds.), Puertos Antiguos y Comercio Marítimo: 249-262, Actas III
Jornadas Internacionales de Arqueología Subacuática, Valencia, Universidad de Valencia.

Pérez Ballester, J. (2000): “Cerámicas de barniz negro de los niveles republicanos del Anfiteatro (Cartagena)". La Cerámica de Vernis Negre dels segles II i I a.C.: 129-142, Mataró, Museu de Mataró.

Pérez Ballester, J. (2009): "La cerámica de barniz negro", en Bernal, D. y Ribera, A. (eds.) Cerámicas Hispanorromanas. Un estado de la cuestión, I: $263-$ 274, Cádiz, Universidad de Cádiz.

Pérez Ballester, J. y Gómez Bellard, C. (2009): El depósito rural púnico de Can Vicent d'en Jaume (Santa Eulària des Riu, Ibiza), Treballs del Museu Arqueològic d'Eivissa i Formentera, 63, Eivissa, Museu Arqueològic d'Eivissa i Formentera.

Pérez Ballester, J. (e.p.): "Análisis arqueométricos de cerámicas oxidantes engobadas de Cerdeña e Ibiza". Opera Fictiles. Estudios transversales sobre cerámicas antiguas en la península Ibérica, IV Congreso Internacional de la SECAH, Valencia 2628 de abril de 2017.

Principal i Ponce, J. (1998): Las importaciones de vajilla fina de barniz negro en la Cataluña sur y occidental durante el s. III a.C., BAR International Series, 729.Oxford, Archeopress.

Ramon, J. (1993): "Barrio industrial de la ciudad púnica de Ibiza: el taller AE-20", Cuadernos de Prehistoria y Arqueología Castellonenses 15: 247-285.

Ramon, J. (1994): El pozo púnico del "Hort d'en Xim" (Eivissa), Trabajos del Museo Arqueológico de Ibiza 32, Ibiza, Museo Arqueológico de Ibiza.

Ramon, J. (1997): FF-13. Un taller alfarero de época púnica en Ses Figueretes (Eivissa), Treballs del Museu Arqueològic d'Eivissa i Formentera 39, Eivissa, Museu Arqueològic d'Eivissa i Formentera.

Ramon, J. (1998a): "La facies cerámica de importación en Eivissa durante el s. III" en Ramon, J., Sanmartí, J., Asensio, D., Principal, J. (eds.) Les facies cerámiques d'importació a la costa ibèrica, les Balears $i$ les Pitiuses durant el segle III a.C. $i$ la primera meitat del segle II a.C.: 157-173, Arqueomediterrània, 4, Barcelona, Universidad de Barcelona.

Ramon, J. (1998b): "Barrio industrial de la ciudad púnica de Eivissa: el taller AE-20", en Costa, B. y Fernández J.H. (eds.) Misceláneas de Arqueología Ebusitana, I: 167-215, Ibiza, Museu Arqueològic d'Eivissa i Formentera.

Ramon, J. (2012a): "La cerámica púnico-ebusitana en época tardía (siglos III-I a.C.)", en Bernal, D. y Ribera, A. (eds.) Cerámicas Hispanorromanas II. 
Producciones regionales: 583-617, Cádiz, Universidad de Cádiz.

Ramon, J. (2012b): "Perduraciones y cambios en las producciones cerámicas tardopúnicas en el extremo occidente mediterráneo". En Mora, B. y Cruz, G. (coords.), La etapa neopúnica en Hispania y el Mediterráneo Occidental: identidades compartidas: 223-258, Sevilla, Universidad de Sevilla.

Ramos Suárez, M.J. y García Vargas, E. (2014): “Las imitaciones de vajilla de barniz negro en el Valle del Guadalquivir", en García Fernández, F.J. y García Vargas F. (eds.) Comer a la moda. Imitaciones de vajilla de mesa en Turdetania y la Bética Occidental durante la Antigüedad (s. VI a.C. - VI d.C.):239270, Col.lecció Instrumenta, 46, Barcelona, Universitat de Barcelona.

Rhigini Cantelli, V. (1981): "Su alcuni documenti fittili di Tharros", Rivista di Studi Fenici 9: 85-87.

Roppa, A. (2013): Comunità urbane e rurali nella Sardegna punica di età ellenistica, Saguntum, Extra 14, Valencia, Universidad de Valencia.

Rouillard, P.; Espinosa, A. y Moratalla, J. (2014): Villajoyosa Antique (Alicante, Espagne). Territoire et Topographie. Le sanctuaire de La Malladeta. Collection Casa de Velázquez, 141, Madrid, CNRS.

Ruiz Valderas, E. (2000): Las cerámicas campanienses de Carthago Nova. El contexto histórico-arqueológico, Tesis Doctoral, Universidad de Murcia. Inédita.

Sáez Romero, A.M. (2014): “Imitaciones en las vajillas de mesa en la Bahía de Cádiz desde la transición tardoarcaica hasta la época tardopúnica. Actualización de los datos y nuevas propuestas", en García Fernández, F.J. y García Vargas F. (eds.) Comer a la moda. Imitaciones de vajilla de mesa en Turdetania y la Bética Occidental durante la Antigüedad (s. VI a.C. - VI d.C.): 33-78, Col.lecció Instrumenta, 46, Barcelona, Universitat de Barcelona.

Sparkes, B.A. y Talcott, L. (1970): Plain an black pottery, The Athenian Agora XII, 2 vols., Princeton /
New Jersey, American School of Classical Studies at Athens.

Tarradell, M. y Font, M. (2000): Necrópolis rurales púnicas en Ibiza, Treballs del Museu Arqueològic d'Eivissa i Formentera 45, Eivissa, Museu Arqueològic d'Eivissa i Formentera.

Tronchetti, C. (1991): "La cerámica a vernice nera di Cagliari nel IV en el III sec. a.C.: importazioni e produzioni locali", en Atti del II Congresso di Studi Fenici e Punici, vol. 3: 1271-1278, Roma, Istituto di Studi Fenici.

Tronchetti, C. (2001): "Una produzione di ceramica a vernice nera a Cagliari tra III e II sec. A.C.: la Cagliari 1", en Architettura arte e artigianato nel Mediterraneo dalla Preistoria all'Alto Medioevo:275-300, Atti Tavola Rotonda in memoria di Giovanni Tore (Cagliari 1999), Oristano, S'Alvure edizioni.

Tronchetti, C. (2008): "La ceramica greca dell'US 500", en Campanella, L. (ed.) Il cibo nel mondo fenicio e púnico d'occidente. Un'indagine sulle abitudini alimentari attraverso l'analisi di un deposito urbano di Sulky in Sardegna: 189-194, Pisa-Roma, Fabrizio Serra Editore.

Tronchetti, C. (2014): "Il problema delle imitazioni ceramiche nella Sardegna fenicia e púnica. Imitazioni da originali greci e indigeni", en Graells, R.; Krueger, M.; Seuma, G. y Scortino, G., (eds.), El problema de "las imitaciones" durante la protohistoria en el mediterráneo centro-occidental. Entre el concepto y el ejemplo: 121-130, Iberia Archaeologica, 18, Berlin, Deutsche Archäologisches Institut Madrid.

Van Dommelen, P. y Sharpe, L. (2004): "Surveying Punic rural settlement: the Terralba Rural Settlement Project, Sardinia", Antiquity 78, http:/www. antiquity.ac.uk/ProjGall/vandommelen/ (14 de septiembre 2015).

Vouillemot, G. (1965): Reconnaissances aux échelles puniques d'Oranie, Autun, Musée Rolin. 